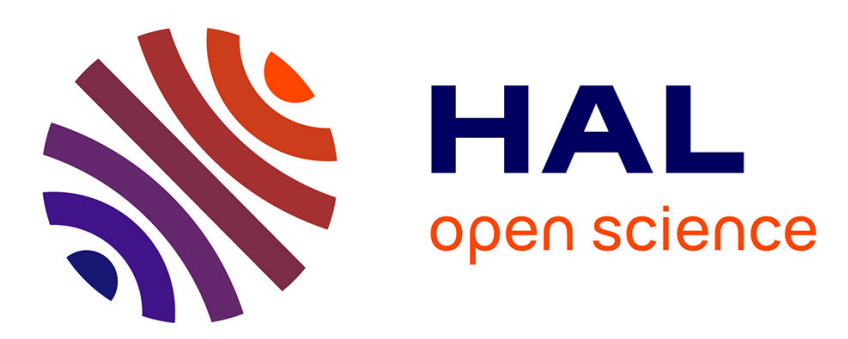

\title{
Self-awareness and the medial temporal lobe in neurodegenerative diseases
}

Chantal Chavoix, Ricardo Insausti

\section{To cite this version:}

Chantal Chavoix, Ricardo Insausti. Self-awareness and the medial temporal lobe in neurodegenerative diseases. Neuroscience and Biobehavioral Reviews, 2017, 78, pp.1-12. 10.1016/j.neubiorev.2017.04.015 . inserm-02135417

\section{HAL Id: inserm-02135417 https://www.hal.inserm.fr/inserm-02135417}

Submitted on 21 May 2019

HAL is a multi-disciplinary open access archive for the deposit and dissemination of scientific research documents, whether they are published or not. The documents may come from teaching and research institutions in France or abroad, or from public or private research centers.
L'archive ouverte pluridisciplinaire HAL, est destinée au dépôt et à la diffusion de documents scientifiques de niveau recherche, publiés ou non, émanant des établissements d'enseignement et de recherche français ou étrangers, des laboratoires publics ou privés. 


\section{Self-awareness and the medial temporal lobe in neurodegenerative diseases}

\section{Chantal Chavoix $^{\mathrm{a}, *}$ and Ricardo Insausti ${ }^{\mathrm{b}}$}

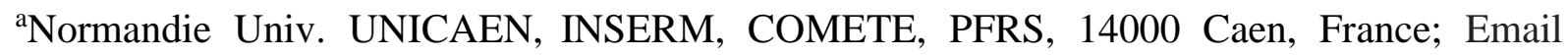
address: chantal.chavoix@inserm.fr

${ }^{\text {b} H u m a n ~ N e u r o a n a t o m y ~ L a b o r a t o r y, ~ S c h o o l ~ o f ~ M e d i c i n e ~ a n d ~ C R I B, ~ U n i v e r s i t y ~ o f ~ C a s t i l l a-L a ~}$ Mancha, Almansa 14, 02006, Albacete, Spain; Email address: ricardo.insausti@uclm.es

\section{Corresponding author: Chantal Chavoix}

Address: INSERM U1075, COMETE, PFRS, 2 rue des Rochambelles, 14032 Caen cedex, France. Phone\#: +33 2.31.56.81.31

Email address: chantal.chavoix @inserm.fr

Key Words: hippocampus; amygdala; entorhinal cortex; perirhinal cortex; parahippocampal gyrus; temporal pole

Abbreviations: AD, Alzheimer's disease; FTD, Frontotemporal dementia; bvFTD, behavioural variant of FTD; HD, Huntington's disease; MCI, mild cognitive impairment; MTL, medial temporal lobe; PD, Parkinson's disease; ALS, amyotrophic lateral sclerosis 


\begin{abstract}
Accurate self-awareness is essential for adapting one's behaviour to one's actual abilities, to avoid risky behaviour. Impaired self-awareness of deficits is common in neurodegenerative diseases. Numerous studies show an involvement of midline cortical areas in impaired selfawareness. Among the other brain regions implicated stand the medial temporal lobe (MTL) structures (i.e. hippocampus, amygdala, and temporopolar, entorhinal, perirhinal and posterior parahippocampal cortices). This review aims at evaluating the role of those structures in selfawareness in neurodegenerative diseases. To this aim, we briefly review impaired selfawareness in neurodegenerative diseases, give a neuroanatomical background on the MTL structures, and report those identified in neuroimaging studies on self-awareness. The MTL shows neuropathological, and structural or functional changes in patients who overestimate their abilities in the cognitive, socio-emotional or daily life activities domains. The structures implicated differ depending on the domain considered, suggesting a modality-specific involvement. The functional significance of the findings is discussed in view of the neuroanatomical networks of the MTL and in the context of theoretical models of selfawareness.
\end{abstract}




\section{Contents}

1. Introduction 4

2. Impaired self-awareness in neurodegenerative diseases 5

2.1. Methodological assessment procedures 5

2.2. Clinical data 6

3. Medial temporal lobe and awareness in neurodegenerative diseases 10

3.1. Anatomical constitution of the medial temporal lobe 11

3.2. Correspondence of neuroimage and anatomical terms 11

3.3. Neuroimaging studies that implicated the medial temporal lobe in self-awareness $\begin{array}{ll}\text { in neurodegenerative diseases } & 12\end{array}$

3.4. Connectivity of the MTL structures 15

4. Functional interpretation of the neuroimaging findings on self-awareness in $\begin{array}{ll}\text { neurodegenerative diseases } & 17\end{array}$

5. Future directions and conclusion 24

$\begin{array}{ll}\text { Acknowledgements } & 26\end{array}$

$\begin{array}{lr}\text { References } & 29\end{array}$ 


\section{Introduction}

Awareness can be defined as "a reasonable or realistic perception or appraisal of one's situation, functioning or performance, or of the resulting implications, expressed explicitly or implicitly" (Clare et al., 2011). Accurate self-awareness is essential for optimal daily life activities, as it allows adapting individual behaviour to different situations according to one's actual abilities. Accurate self-awareness thus prevents from risky or withdrawal behaviour.

Impaired self-awareness may have significant adverse effects. For instance, overestimation of one's driving or postural abilities increases the risk of driving or fall accident (Morone et al., 2014; Horrey et al., 2015), and overestimation of one's cognitive abilities may negatively impact numerous daily life activities such as managing finances or shopping (Hoofien et al., 2004); likewise, inaccurate estimation of one's social skills may affect social communication. Conversely, underestimation of these same abilities may lead to a loss of autonomy and social isolation. However, overestimation is more common than underestimation of one's abilities (e.g. Michon et al., 1994; Okonkwo et al., 2008). Unawareness of deficits can be detrimental to the rehabilitation of brain damage. It also affects the patient's family and friends' quality of life, namely by increasing the caregivers' burden (Rymer et al., 2002). Although impaired self-awareness should thus be considered as a symptom of great importance, it is often neglected, mainly because of the lack of knowledge of its pathophysiology, treatment and prevention.

Impaired self-awareness has been reported in a number of neurological and neuropsychiatric disorders (e.g. stroke, neurodegenerative diseases, traumatic brain injury, schizophrenia), and in various domains (e.g. sensori-motor, cognitive, socio-emotional, and daily life activities). This clearly demonstrates that there is no "awareness centre" in the brain, 
but rather suggests that self-awareness implies several areas likely organized in specific networks.

Attempts to unravel the brain networks involved in impaired self-awareness have been the focus of a number of studies. The medial prefrontal cortex is the most constantly identified region within this network. Other cortical and sub-cortical areas have been implicated. However, their role in self-awareness remains obscure (see Northoff et al., 2006 for meta-analysis). Among them, the medial temporal lobe (MTL) structures stand out, namely the hippocampus, amygdala, and surrounding cortices, i.e. the temporopolar, entorhinal, perirhinal and posterior parahippocampal cortices.

This review aims at providing an in depth analysis of the putative role of MTL in impaired self-awareness in neurodegenerative diseases, because this symptom is common in these conditions that are often associated with MTL damage albeit to varying degrees. Moreover, involvement of MTL in impaired self-awareness has never been explored specifically. Thus, we will focus on four of such neurodegenerative diseases: Alzheimer's disease (AD), frontotemporal dementia (FTD), Parkinson's disease (PD), Huntington's disease (HD), and amyotrophic lateral sclerosis (ALS). Mild cognitive impairment (MCI) has also been included in the review because many symptoms are shared and quite a few individuals will convert to AD.

\section{Impaired self-awareness in neurodegenerative diseases}

\subsection{Methodological assessment procedures}

The most frequently used method of assessing self-awareness is to compare the participant's judgments about its own abilities and behaviour with parallel ratings made by an 
informant (e.g. spouse and caregiver). Several validated questionnaires and standardized procedures have been developed (eg, Wilson et al. 1989, Clare et al. 2002, Starkstein et al. 2006, Bramham et al. 2009). This method, however, lacks direct measurement of performance, and a range of psychological and social factors influence ratings (Clare et al., 2011). Among the other methods employed in the assessment of self-awareness, the most appropriate is probably the comparison between subjective and objective data, i.e. performance ratings made by the participant $v s$. actual tests scores. This method provides a more useful indicator of awareness than the participant-informant discrepancy score (Dalla Barba et al., 1995).

\subsection{Clinical data}

Patients with neurodegenerative diseases tend to overestimate their functional abilities in various domains (e.g. cognition, behaviour, socio-emotion, daily life activities) (Eslinger et al., 2005; Roberts et al., 2009, Sitek et al., 2014 and Starkstein, 2014 for reviews). However, severity and domains of unawareness may vary according to the type of neurodegenerative disease considered, the severity of the disease or along the course of a given disease. Within a given neurodegenerative disease, discrepant results have often been reported, mainly because of differences in the sample characteristics, assessment methods, concept of unawareness, and aim of the studies.

Self-awareness in individuals with Mild Cognitive Impairment. A recent meta-analysis found no difference in awareness between MCI and healthy subjects but highlighted that assessment technique and cognitive status influence the level of awareness (Piras et al., 2016). Vogel and colleagues (2014) reported that about $60 \%$ of individuals with amnestic MCI exhibit symptoms of cognitive unawareness, $12 \%$ of which show severe loss of awareness. Only $36 \%$, mainly of the amnestic type, overestimate their abilities in daily life activities, and this was 
found only for relatively complex functional activities (i.e. financial management or driving abilities, Okonkwo et al., 2009). Some studies, but not all, indicate that overestimation of abilities might be a predictor of conversion from MCI to dementia (see Roberts et al., 2009 and Jacus et al., 2014 for reviews). Some individuals with MCI underestimate their cognitive performance and abilities in daily life activities (Kalbe et al., 2005, Okonkwo et al., 2008; Roberts et al., 2009). Depression, that is common in individuals with MCI, could partly account for this underestimation (Okonkwo et al., 2008; Roberts et al., 2009).

Self-awareness in Alzheimer's disease. Impaired self-awareness, here characterized only by overestimation of abilities, can be observed since the early stages of the disease (Amanzio et al., 2011), although the degree of impaired self-awareness varies greatly from one patient to another, even at a similar stage of the disease. Overestimation of cognitive performance in patients with AD has been observed in most studies (e.g. Vogel et al., 2004; Kalbe et al., 2005; Salmon et al., 2006; Shany-Ur et al., 2014; Morris et al., 2016). Greater awareness of cognitive impairment has been related to better episodic memory and higher level of education (Salmon et al., 2006). Patients in the early stages of $\mathrm{AD}$ also overestimate their empathy, social skills and social behaviour. The following findings are more controversial: overestimation of abilities in daily life activities (e.g. Shany-Ur et al., 2014), association between impaired self-awareness and executive dysfunction, symptoms of depression, apathy and disinhibition (Michon et al., 1994; Salmon et al., 2006; Amanzio et al., 2011), and worsening of unawareness with disease progression (e.g. Michon et al., 1994; Clare et al., 2013). In most domains, patients with AD are less aware of their deficits than individuals with MCI (e.g. Zamboni et al., 2013). However, a comparable level of memory awareness was sometimes reported, especially in individuals with amnestic MCI and patients with mild AD (Vogel et al., 2004; also see Roberts et al., 2009, Jacus al., 2014, and Starkstein, 2014 for reviews). 
Self-awareness in Frontotemporal dementia. Impaired self-awareness is a prominent feature of FTD that has been found in over three quarters of the patients (Piguet et al., 2009). Impaired self-awareness varies, however, considerably across FTD subtypes and domain of awareness. Patients with the behavioural variant ( $b v F T D$ ) show the most severe loss of self-awareness. Although overestimation of competence in the socio-emotional domain seems to be the most prominent feature, patients with bvFTD also often exhibit early and severe overestimation of cognitive abilities (Eslinger et al., 2005; Hornberger et al., 2014; Shany-Ur et al., 2014). Patients with progressive non-fluent aphasia are the least affected. However, they can show unawareness of apathy (Eslinger et al., 2005) and overestimation of emotional and interpersonal functioning (Shany-Ur et al., 2014). Patients with semantic dementia have a relatively accurate awareness of their language and cognitive impairment, as well as level of functioning in daily life activities (Eslinger et al., 2005; Shany-Ur et al., 2014). However, they show sometimes a light unawareness of their socio-behavioural changes (Eslinger et al., 2005), especially in those with predominant right-sided atrophy (Hodges and Patterson, 2007). Patients with bvFTD appear less aware of their deficiencies than patients with AD (Eslinger et al., 2005; Hornberger et al., 2014). Minimal discrepancies were however reported between patients with language subtypes of FTD and patients with AD (Hornberger et al., 2014): lower self-awareness was found in patients with $\mathrm{AD}$ or language subtypes of FTD depending of the domain considered (e.g. lower cognitive self-awareness in $\mathrm{AD}$ and lower self-awareness in the socio-emotion domain in FTD) (Eslinger et al., 2005).

Self-awareness in Parkinson's disease. Between $23.3 \%$ and $92 \%$ of the patients are unaware of levodopa-induced dyskinesias (Vitale et al., 2001; Amanzio et al., 2010; Pietracupa et al., 2013). Awareness of bradykinesia is better preserved (Amanzio et al., 2010). Discrepancy between patient and informant's rating of dyskinesias could however result from their respective perception of dyskinesias (less a handicap than bradykinesia for the patient $v S$. 
extremely unpleasant for the patient's relatives), as suggested in patients with PD with mild dyskinesias (Vitale et al., 2001). Unawareness of movement disorders is greater in "on" than in “off" state and in patients with low executive function (Amanzio et al., 2010). However, it may also occur in PD patients with normal cognition (Pietracupa et al., 2013). Overestimation of competence in daily life activities has also been reported in non-demented patients with PD (Leritz et al., 2004). The few studies in the cognitive field indicate accurate self-awareness of general cognition and memory performance (Flashman, 2002; Kudlicka et al., 2013). In case of executive dysfunction, patients with PD can, however, overestimate their executive performance (Kudlicka et al., 2013). Compared to patients with AD, impaired self-awareness in patients with PD is less severe and more strongly related to poor cognitive function (Flashman, 2002).

Self-awareness in Huntington's disease. Patients with HD often underestimate their involuntary movements (Flashman, 2002; Sitek et al., 2014 for review). They may also underestimate apathy, impulsivity, cognitive deficits, executive-type behavioural dysfunction, and degree of functional impairment. Cognitive impairment, in particular executive dysfunction, may be an important contributory factor of this unawareness. Nonetheless, patients with HD usually show accurate awareness of their depression and irritability. Impaired awareness of dyskinesias is related to disease duration and severity (Vitale et al., 2001), and is more frequent (Vitale et al., 2001) and more severe in patients with HD than in those with PD (see Sitek et al., 2014 for review).

Self-awareness in amyotrophic lateral sclerosis. Although self-awareness has rarely been investigated in ALS, a few studies reported unawareness of behavioural changes (Woodley et al., 2010) as well as motor and cognitive abilities (Ichikawa et al., 2013) in ALS patients with FTD. Reduced awareness of cognitive deficit was also found in non- 
demented ALS patients which was associated to a deficit in affective and/or cognitive theory of mind (van der Hulst et al., 2015).

\section{Medial temporal lobe and awareness in neurodegenerative diseases}

Brain networks of self-awareness in neurodegenerative diseases were mainly investigated by assessing the brain correlates of self-awareness (using structural MRI or metabolic FDG-PET imaging for instance) or in participants performing a self-awareness task (e.g. fMRI). Up to date, there is only one postmortem anatomical study (Marshall et al., 2004), and it provided little significant information due to various methodological limitations (e.g. only four areas investigated, etc.).

Structural or functional changes in the MTL have been found in patients with neurodegenerative diseases who show impaired self-awareness. However, these findings have rarely been interpreted, probably because of the unfamiliar anatomical delineation of the MTL structures and the connections they present with brain areas that have already been reported involved in self-awareness. An in-depth background in the MTL neuroanatomy is thus required for a better understanding of the neuroimaging results, and consequently of the MTL implication in self-awareness deficits. For this reason, we will first recall the anatomical constitution of the MTL and clarify the correspondence between neuroimage and anatomical terms. Then, we will present the neuroimaging studies on self-awareness in neurodegenerative diseases in which MTL regions have been identified, together with a neuroanatomically contextualized reinterpretation. Finally, we will describe the connectivity of the MTL structures necessary for the subsequent functional interpretation of the neuroimaging findings. 


\subsection{Anatomical constitution of the medial temporal lobe}

The MTL is an extensive and heterogeneous region that runs along the rostrocaudal extent of the ventromedial aspect of the temporal lobe. It includes non-cortical and cortical areas, as shown in Figure 1 that represents the medial aspect of a human brain hemisphere with the MTL areas depicted at the macroscopic level and the MRI correspondence: 1) the amygdala, a subcortical structure made up of distinct nuclei that is buried in the depth of the anterior MTL, rostral to the hippocampus; 2) the cortex located at the ventromedial surface of the temporal lobe that includes the temporopolar, perirhinal and parahippocampal cortices; altogether, these three cortical areas are called "parahippocampal region"; and 3) the hippocampal formation composed of different structural and functional parts (dentate gyrus, hippocampal fields CA1, CA2 and CA3, subiculum, presubiculum and parasubiculum, and the entorhinal cortex) (Insausti and Amaral, 2012).

\subsection{Correspondence of neuroimage and anatomical terms}

It is necessary to clarify that the term parahippocampal region is not a synonymous of parahippocampal gyrus, which is commonly used in neuroimaging studies. While the former is a strip of temporal cortex medial to the remainder of the temporal lobe, the latter is a macroscopic, gross anatomical term that defines a gyrus made up of several cortical regions. Therefore, the parahippocampal gyrus is heterogeneous and includes anteriorly, the entorhinal and perirhinal cortices, and posteriorly, the parahippocampal cortex that is called "posterior parahippocampal cortex" in the present review to avoid confusion with the parahippocampal gyrus. It is also important to highlight that the term temporopolar cortex is distinct from the term temporal pole used in neuroimaging studies. Temporopolar cortex only corresponds to the most anterior and ventromedial part of the temporal pole as described previously (Insausti et 
al., 1998; Blaizot et al., 2010; Frankó et al., 2014; Insausti, 2014). Description of the MTL structures for neuroimaging studies with delineation on MR images can be found in Franko et al.'s (2014) study.

In the next sections, only the temporopolar cortex will be considered within the temporal pole, and the parahippocampal gyrus will be addressed in terms of entorhinal, perirhinal and posterior parahippocampal cortices whenever possible.

\subsection{Neuroimaging studies that implicated the medial temporal lobe in self- awareness in neurodegenerative diseases}

Few studies exist in which MTL structures have been reported as associated to a change in self-awareness. Significantly, and to the best of our knowledge, no study exists in which a specific assessment of the role of MTL in self-awareness has been attempted. In our search for publications dealing with self-awareness and the MTL we used the PubMed bibliographic resource by using the terms "self-awareness", "anosognosia", "brain", "hippocampus", "temporal lobe", “temporal pole”, amygdala, "entorhinal cortex", perirhinal cortex", "parahippocampal gyrus", "Alzheimer disease", "mild cognitive impairment", "frontotemporal dementia", "Parkinson disease", "Huntington disease", and "amyotrophic lateral sclerosis".

Table I shows the nine neuroimage studies that reported structural or functional changes in the MTL structures in relation to impaired self-awareness, together with other brain areas involved. These studies focused on the cognitive, daily life activities, behavioural, or socio-emotional domains. As can been seen in Table I, there is a high heterogeneity in the methodology, the series of patients and the neurological disorders to which the impairment of self-awareness is associated. All studies included patients with AD. Two of them also included 
individuals with MCI, and three of them also included patients with other neurodegenerative disease (FTD and corticobasal syndrome). Self-awareness was measured by discrepancy scores between patient's and informant's rating in seven studies, and by comparing subjective and objective cognitive scores in only one study; the ninth study was based on self-evaluation of cognitive impairment by the patient, with the objective cognitive measurements used as confounding variables. The neuroimaging techniques include structural MRI $(n=3)$, FDG-PET $(n=2)$, functional MRI activation $(n=3)$, resting-state fMRI $(n=1)$, and neuropathology $(n=1)$. Despite the high heterogeneity of the studies in which the MTL has been implicated, a number of regions closely related both at the anatomical and functional levels have been identified. Likewise, some of the studies indicate differences in the rostrocaudal level of the MTL. Results appear less divergent when analyzed by awareness domain.

Of note, presentation of the results in these reports rarely allows precise identification of the areas involved within the parahippocampal gyrus (i.e. entorhinal, perirhinal or posterior parahippocampal cortices), and which anterior-posterior part of the hippocampus or parahippocampal gyrus was concerned. However, the brain coordinates reported and the illustrative images displayed in some studies enabled us to specify the MTL structures involved, based on the SPM Anatomy toolbox (https://www.fz-juelich.de/ime/spm_anatomy_toolbox, Eickhoff et al., 2005), the Talairach Daemon software (http://www.talairach.org, Lancaster et $a l ., 2000)$, and with the help of neuroanatomical data and MTL boundaries previously described (Insausti et al., 1998; Frankó et al., 2014). Based on this procedure, neuroanatomically contextualized reinterpretation of the reported loci of interest within the MTL has been included in Table I that is further summarized and commented below.

Self-awareness of cognitive deficits. The six studies in this field (Marshall et al., 2004; Salmon et al., 2006; Amanzio et al., 2011; Ries et al., 2012; Zamboni et al., 2013; Perrotin et al., 2015), all performed in $\mathrm{AD}$ (two studies also included MCI), show a great heterogeneity 
in the measurement of awareness (e.g. different cognitive questionnaires), brain imaging methods (e.g., the four fMRI studies used different approaches), and statistical analyses performed. There were two studies on functional brain connectivity, but none of them used diffusion tensor imaging. Despite the great heterogeneity in the methods used, the MTL structures involved were overall similar and did not differ for memory and global cognition. Laterality of the findings also varies between studies. Indeed, left, right and bilateral involvements were all observed for the hippocampus (Marshall et al., 2004; Ries et al., 2012; Zamboni et al., 2013; Perrotin et al., 2015), while involvement of left and right side were both found for the parahippocampal gyrus (Salmon et al., 2006; Amanzio et al., 2011; Perrotin et al., 2015). Thus, taken into account our neuroanatomically contextualized reinterpretation, cognitive self-awareness seems to engage the anterior and posterior hippocampus as well as the perirhinal and posterior parahippocampal cortices, on both sides.

Self-awareness of daily life activities. The only study in this field is a structural MRI study that investigated multiple domains in patients with AD, FTD and healthy controls (Shany-Ur et al., 2014). Atrophy related to overestimation of competencies for daily life activities such as preparing meals, managing personal finances or driving includes the posterior hippocampus, posterior parahippocampal cortex and amygdala, only on the right side.

Self-awareness of behavioural disturbances. Upon classification into aware and unaware Alzheimer's patients based on cognitive questions about cognitive function and performance, and behavioural questions about changes in interests and mood (e.g., more selfish or more irritable), a fMRI study showed greater activation in the right posterior parahippocampal cortex of unaware Alzheimer's patients during a go/no-go inhibitory task, which was interpreted as compensatory mechanisms (Amanzio et al., 2011). Justification for the use of a go/no-go task was based on the theoretical models of awareness that highlight the contribution of the executive system in metacognitive abilities related to awareness 
(see below the section of functional interpretation of the imaging data), the close links between cognitive unawareness and behavioural problems such as apathy, and the presence of apathy and disinhibition as prominent features in their unaware patients.

Self-awareness in the socio-emotional domain. The two studies in this field, that used structural MRI in patients with AD, FTD, and corticobasal syndrome, reported bilateral atrophy in the anterior MTL only (Hornberger et al., 2014; Sollberger et al., 2014). More precisely, and taking into account our neuronatomically contextualized reinterpretation, the involved areas were the temporopolar cortex (as part of the temporal pole), amygdala, anterior hippocampus, as well as the perirhinal cortex and probably also part of the entorhinal cortex. The specific structure and side of the brain involved were dependent, however, on the socioemotional process under study. For instance, the hippocampus was part of the neural substrates of self-awareness of one's emotion, mainly targeting empathy, but not of one's social behaviour, tapping into social appropriateness and inhibitory functioning (Hornberger $\boldsymbol{e t}$ al., 2014).

Functional interpretation of these findings requires detailed knowledge about the connectivity of the MTL structures.

\subsection{Connectivity of the MTL structures}

Figures 2 and 3 summarize the main cortical connections of the MTL structures The parahippocampal region is a closely related system to the hippocampal formation (Insausti et al., 1987a). The three cortical regions that form the parahippocampal region (i.e., temporopolar, perirhinal and posterior parahippocampal cortices) contribute approximately with two-thirds of the polymodal sensory input to the entorhinal cortex (Insausti et al., 1987a). The entorhinal cortex is considered as the gateway for the entrance of most of the cortical input to the dentate gyrus and CA fields through the perforant path. This system constitutes the main interface 
between the neocortex and the hippocampus. A small amount of direct cortical input terminates in the border between CA1 and the subiculum (Insausti and Munoz, 2001). In addition to the parahippocampal region itself, other broad polymodal association cortices connect with the entorhinal cortex, specifically the orbitofrontal and medial frontal cortices, anterior cingulate area, retrosplenial cortex and medial parietal cortex (precuneus), anterior insular cortex, superior temporal gyrus, all providing dense cortical input to the entorhinal cortex (Amaral et al., 1983; Insausti and Amaral, 2008). Interestingly, these polymodal association cortices have been reported as key players in brain networks subserving self-awareness. Moreover, the hippocampal formation receives a substantial direct input from subcortical centers, such as the basal forebrain, thalamus, hypothalamus and brainstem (Insausti et al., 1987b). The cortices of the parahippocampal region also present a very extensive and rich set of connections with other unimodal and polymodal association cortices (Suzuki and Amaral, 1994). Therefore, the number of cortical areas and regions able to interact directly or indirectly with the hippocampal formation through the parahippocampal region is very extensive. As a brief summary, the temporopolar cortex is closely related to the auditory association cortex, orbitofrontal and medial frontal, anterior insular, temporal cortices, and pulvinar nucleus of the thalamus (Morán et al., 1987; Kondo et al., 2003) while the perirhinal and posterior parahippocampal cortices are strongly connected to the inferotemporal, and parietal cortices respectively.

The amygdala, and in particular its polymodal sensory associative part (i.e., lateral and basal nuclei) has widespread reciprocal connections with numerous cortical areas. Basically, all cortical areas send projections to the lateral nucleus of the amygdala (Amaral and Insausti, 1992), and this information is relayed through the basal nucleus of the amygdala, which connects with almost all cortical areas (Amaral and Price, 1984). The amygdala also presents distinct connections with the primary motor and sensory cortices, what distinguishes 
the set of connections (and possibly networks) associated to the amygdala from the parahippocampal region and hippocampal formation of the MTL.

In conclusion, numerous cortical association areas, either unimodal or polymodal, are able to reciprocally connect very extensively, directly or indirectly, through the parahippocampal region with the hippocampal formation, mainly by projections to the entorhinal cortex.

A note of caution should be brought up as the detailed connectivity alluded to above has been determined in neuroanatomical studies in nonhuman primates, which have a close similarity and homology with the MTL of humans (Insausti et al., 1995; Blaizot et al., 2004, 2010; Insausti and Amaral, 2012; Insausti, 2014). However, the great expanse of association cortices in the human brain prevents to draw simplistic conclusions from the nonhuman primate neuroanatomy. Notwithstanding, the set of nonhuman primate neuroanatomical connections serves as a general framework for understanding human connectivity.

In neuroimaging studies, the MTL regions are usually referred to as the amygdala, hippocampus, temporal pole and parahippocampal gyrus. As described above, these names are very general and lack precision for the detailed identification of the MTL anatomical structures. Therefore, functional interpretation of the reported data is not easy since this neuroimage structural identification is imprecise. Besides the faulty identification fails to orient the connectivity to possible networks implicated in self-awareness. This can partly explain why most neuroimaging studies that show changes in the MTL do not elaborate on the functional interpretation of these findings.

\section{Functional interpretation of neuroimaging findings on self-awareness in neurodegenerative diseases}


Three main salient points emerge from the review of the above neuroimaging studies. First, despite the numerous differences in the methodological procedure used in the different studies (e.g. population, awareness assessment, imaging techniques, statistical analyses), the MTL structures that show structural or functional changes in patients who overestimate their abilities are essentially consistent from one study to the other, especially when analysed by awareness domain. Second, structural or functional changes in the MTL structures in relation to reduced self-awareness do occur, and the involved MLT structures differ depending on the awareness domain considered. Third, changes in the MTL regions in relation to reduced self-awareness seem to have been shown mainly in neurodegenerative diseases in which the MTL is affected and when the concerned awareness domain engages the MTL. These findings will be discussed in view of the most recent theoretical model of selfawareness.

It must be said in advance that only a few imaging studies have reported changes in MTL in relation to self-awareness, and that direct evidence for the putative role of the MTL on self-awareness problems is scarce. However, it is perfectly possible to associate the MTL with areas significantly related to self-awareness based on the present neuroimaging findings and connectivity patterns known from anatomical data in nonhuman primates (see above) and functional studies.

There exists a significant overlap between the MTL structures associated to the overestimation of cognitive abilities and those known to be involved in cognition (i.e. anterior and posterior parahippocampal gyrus, and hippocampus). The same holds true for the MTL areas involved in the overestimation of socio-emotional abilities and socio-emotional behaviour (i.e. amygdala, temporopolar and perirhinal cortices, and anterior part of hippocampus). Indeed, the key-role of the hippocampus in cognition, especially in memory, is widely recognized (Squire et al., 2004). Although less referred to in clinical studies, the perirhinal, entorhinal and 
posterior parahippocampal cortices also play an important role in memory (Meunier et al., 1993; Blaizot et al., 2000; Chavoix et al., 2002; Squire et al., 2004; Rauchs et al., 2006). The role of the amygdala in social emotion processing (Aggleton, 1993; Meunier et al., 1999; Ruby and Decety, 2004) and that of the temporal pole and perirhinal cortex in socio-emotional processes (Meunier et al., 2006; Olson et al., 2007) are well acknowledged. Furthermore, temporopolar cortex is involved in perspective taking tasks (Olson et al., 2007; Ruby and Decety, 2004), and, together with the perirhinal cortex, in semantic knowledge (Hodges and Patterson, 2007; Rauchs et al., 2006; Olson et al., 2007), which is closely linked to taking a third-person perspective (Sollberger et al., 2014). This overlap between involvement of MTL structures in a given domain and their involvement in self-awareness in the same domain adds further support to the suggestion that neural substrates of self-awareness are partly modality specific (Morris and Mograbi, 2013; Sollberger et al., 2014).

The atrophy in the amygdala, hippocampus and posterior parahippocampal cortex in patients who overestimate their competency in daily life activities (Shany-Ur et al., 2014) is more difficult to interpret. Since completion of daily life tasks requires integration of many functions, involvement of these brain areas might be partly linked to their pivotal anatomical position (see Figures 2 and 3). Thus, these findings could account for the role of the hippocampal formation in relational binding across multiple domains (Davachi, 2006; Olson et $a l ., 2007)$ and that of the amygdala in social aspects of daily life activities (Olson et al., 2007).

The structural and functional changes in the MTL linked to the overestimation of abilities in $\mathrm{AD}, \mathrm{MCI}$ and $\mathrm{FTD}$, as reported in Table I, are reminiscent of the cerebral damage characteristics of each clinical state, and all MTL structures are concerned. Thus, in AD, the perirhinal and entorhinal cortices are the most and earliest affected areas (Braak and Braak, 1991; Van Hoesen et al., 1991); they also show atrophy (Juottonen et al., 1998) and their alteration plays a key role in the pattern of cortical hypometabolism and memory impairment 
of these patients (Meguro et al., 1999, Blaizot et al., 2002). Damage to the hippocampus and posterior parahippocampal cortex occur somewhat later (Braak and Braak, 1991). The parahippocampal gyrus and hippocampus are also affected in the MCI disease process (Mufson et al., 2012).

Regarding FTD, damage to the MTL is a key feature, especially in the bvFTD (Whitwell et al., 2009), which is the form of FTD that presents the most severe loss of awareness (Hornberger et al., 2014; Shany-Ur et al., 2014; Sollberger et al., 2014), as well as in SD (Hodges and Patterson, 2007). The pattern of temporal atrophy in patients with bvFTD predominantly involves anterior temporal regions (Whitwell et al., 2009) but also includes the hippocampal formation and parahippocampal region. The temporopolar and perirhinal cortices as well as the hippocampus and amygdala, also are consistently affected in SD (Hodges and Patterson, 2007). The predominant right involvement of the temporal regions in FTD is, however, not found in the patients unaware of their socio-emotional abilities (Hornberger et al., 2014; Sollberger et al., 2014); this might result from the inclusion of patients with different neurodegenerative diseases in these two studies (i.e., FTD, AD and corticobasal syndrome).

Regarding PD and HD, the few existing imaging studies of self-awareness focused on movement disorders and do not report changes in the MTL (e.g., Maier et al., 2016). Since MTL is not implicated in movement disorders, it confirms that the role of the MTL in selfawareness would likely be limited to its domain of specialization (i.e. mainly memory and socio-emotion).

It seems however that self-awareness in memory and socio-emotional domains do not rely only on MTL. Indeed, amnesic patients with damage restricted to the MTL, such as the famous case $\mathrm{HM}$ and the patient $\mathrm{KC}$, are well aware of their own capacity. In the famous case HM who underwent surgical resection of the MTL as a treatment for intractable temporal lobe 
epilepsy, the temporal lobectomy encompassed the temporopolar, perirhinal and entorhinal cortices, amygdala, and hippocampus bilaterally (Corkin et al., 1997). Despite this extensive temporal lobe resection, patient HM could state: "I do have, well - a lot of trouble remembering things" (Corkin, 2013), a clear indication of self-awareness of memory deficit. Similarly, patient $\mathrm{KC}$ who also shows an extensive and prominent bilateral atrophy in the hippocampal formation and perirhinal cortex 35 years after a traffic accident (Rosenbaum et al., 2005), when questioned about his memory, said that his memory was "pretty lousy"; he also stated "I have no memory of things that just happened" (Schacter, 1991). Thus, both clinical cases imply awareness of their memory deficit. The same holds true for the Klüver-Bucy syndrome with damage mainly restricted to the anterior MTL (bilateral amygdala and temporal pole) (Marlowe et al., 1975) resulting in behavioural and emotional disorders but no unawareness. Unawareness of memory deficits has, however, been reported in patients with lesion restricted to the hippocampal region. Indeed, during the acute phase of transient global amnesia, patients are aware of their disease state but are unable to point to the amnesic nature of their disorder (Hainselin et al., 2012). "Dissociated" type of awareness, with awareness of some type of deficits and unawareness of others, is actually a frequent phenomenon (see Antoine et al., 2004 for review). These various observations suggest either that awareness of memory deficits after selective hippocampal lesion may occur only when there is time for compensation by semantic learning, like in patients HM or $\mathrm{KC}$, or that patients with hippocampal lesion can be aware of memory deficits but they do not accurately perceive the degree of their deficit. Indeed, we cannot exclude that patients $\mathrm{HM}$ and $\mathrm{KC}$ underestimated their memory deficit. To ascertain the role of MTL in self-awareness, it remains to be determined whether unawareness of memory and socioemotional disturbances can occur at distance from selective damage to the MTL as well as without damage in the MTL. 
In contrast, individuals with MCI, AD and FTD present lesions, both within and outside the MTL. This would indicate that unawareness of memory and socio-emotional disturbances might only occur when damage to MTL is associated with brain damage in other brain regions.

As shown in Table I and in agreement with most studies (Jenkins and Mitchell, 2011; van Veluw and Chance, 2014), the medial prefrontal cortex is one of the most important nodes of the neural network implicated in self-awareness, regardless of the domain considered. Interestingly, it has strong interconnections with each component of the MTL (Insausti et al., 1987a; Muñoz and Insausti, 2005; Lavenex et al., 2004; see Figures 2 and 3). Each of these anatomical connections would, however, account for distinct implication in self-awareness. For instance, those between the anterior part of the MTL (temporopolar cortex and perirhinal cortex) and medial prefrontal cortex would play a preferential role in self-awareness requiring semantic knowledge.

The medial prefrontal cortex is also closely interconnected with other association cortices reported to be involved in self-awareness, in particular the anterior cingulate cortex and related areas (see Table I). This interconnectivity between the medial prefrontal cortex and a great expanse of the cortex, including the MTL would play a key role in self-awareness, in agreement with the association of poor memory self-appraisal ability and altered functional connectivity between the medial prefrontal cortex and other cortical structures (Ries et al., 2012). The same holds true for the parietal and temporal association cortices, part of the neural network of theory of mind (see van Veluw and Chance, 2014 for meta-analysis) and also reported in the studies included in Table I (see Figures 2 and 3 for the anatomical connections between MTL and cortical areas). 
Finally, the role of MTL structures in self-awareness can be interpreted in view of the "Cognitive Awareness Model” (CAM) recently revised (Morris and Mograbi, 2013). This model posits that, after local processing of sensory inputs in domain-specific modules (e.g., language, visual, motor), information about current performance is processed in memory systems; information from both episodic and working memory are sent to the "autobiographical conceptual memory systems" that contains lifetime knowledge concerning experienced events. Then, "cognitive comparator mechanisms" that function under executive control allow the comparison between the incoming and personal information, previously stored in the "personal database" as a semantic representation. The output of the comparison leads to the update of the "personal database" in case of mismatch between the two sources of data, and the resulting information is released via the "metacognitive awareness system" to provide awareness of the personal information. Parallel to the "autobiographical conceptual memory systems" that store information about the self, there is a "generic memory system" that stores other material, in particular information about others, that would be under the control of the same higher order comparative and metacognitive awareness systems. It is also suggested that preserved emotional processing is essential to estimate the valence of an event and correctly appraise its final outcome. Consequently, emotional factors would also play a role in error monitoring.

In view of this model, it could be hypothesized that the main function of the MTL in the self-awareness network would be the update of self-knowledge (i.e. individual cognitive and socio-emotional self-knowledge). Damage to MTL would hamper this process. In AD, the loss of memory processes such as recollection of personal experiences and impaired consolidation is known to depend on the MTL structures (Hyman et al., 1984), and their damage would prevent the update of personal knowledge. In addition, patients with AD who are unable to take a third-person perspective would not benefit from general semantic knowledge when asked to evaluate their abilities (Morris and Mograbi, 2013). In FTD, alteration in the semantic system 
would hamper personal semantic knowledge, what would lead to an impaired update of incoming information. Lack of self-awareness in FTD would additionally result from altered social and emotional processes that are supposed to modulate the personal database. Interestingly, a computed tomography study performed in ALS patients with FTD found that impaired cognitive self-awareness, as evaluated by one 8-item scale about motor and cognitive abilities, was associated with enlargement of the anterior and inferior horn sizes of the lateral ventricle, which was interpreted as reflecting MTL atrophy (Ichikawa et al., 2013). This single although interesting study calls for in-depth neuroimaging investigations on self-awareness in ALS. In PD and HD, unawareness of cognitive deficits could result from their impaired working memory, which would not allow appropriate comparison between incoming and stored information. However, the MTL would play at best only a minor role in cognitive unawareness of these patients. Indeed, albeit there are pathological changes in the entorhinal and perirhinal cortices, hippocampus and amygdala in these neurodegenerative diseases (Braak and Braak, 1992; Spargo et al., 1993; Braak et al., 1996), and that several of these areas are involved in working memory (Fuster and Alexander, 1971; Goldman-Rakic, 1992; Chavoix et al., 2002), the MTL is weakly connected with the lateral prefrontal cortex involved in working memory in nonhuman primates (MohedanoMoriano et al., 2015). Nevertheless, the lack of neuroimaging studies regarding impaired selfawareness of cognitive abilities in HD and PD stresses the need for further investigations.

\section{Future directions and conclusion}

In view of the present review, there is a need for further neuroimaging investigations focusing on MTL in the various domains of self-awareness and in the different neurodegenerative diseases. In particular, the search for other brain centres 
involved in self-awareness, as the present endeavour regarding the role played by the MTL, is a potentially fruitful avenue for future studies designed to advance in the knowledge of the biological basis of self-awareness. Special attention should in particular be paid to subcortical structures. Indeed, many reports dealing with self-awareness point to subcortical structures but little is known on their participation. Among the subcortical areas, the amygdala calls for more in-depth studies. Furthermore, other regions and systems outside the MTL are also implicated in memory, but no connection to self-awareness has been yet established. It is also worth testing the potential dissociation between the MTL contribution to self-awareness and that of other brain regions involved in self-awareness, mainly the polymodal association cortices directly connected the MTL such as the orbitofrontal and medial frontal, anterior cingulate, retrosplenial, anterior insular and superior temporal gyrus cortices.

It is likely that more sensitive techniques, as well as longitudinal studies and therapeutic interventions, will allow the emergence of subsequent centres and nodes in a selfawareness widespread network. Comparison among studies and methodologies, along with more homogeneous populations, would be helpful. $\mathrm{n}$ the other hand, more connectivity studies are needed to draw sound conclusions. Finally, recent investigations suggest that the two profiles of impaired awareness (over- and under-estimators) arise from distinct pathological processes (Sollberger et al., 2014; Shany-Ur et al., 2014) and socio-psychological profiles (personal data), all of which stresses the need for further investigations.

As a conclusion, from a meticulous analysis of neuroimaging studies and in light of the anatomical connectivity of the MTL, this review highlights a participation of the MTL in self-awareness in neurodegenerative diseases, which is consistent with the MTL position within the brain networks of self-awareness. Participation of the MTL in self-awareness would mainly derive from its role in the update of self-knowledge, and would concern the memory and socio- 
emotional domains, and likely the daily life activities domains, which are impaired in neurodegenerative diseases.

Acknowledgements: the authors wish to thank the personnel of the Human Neuroanatomy Laboratory of the University of Castilla-La Mancha as well as E Monfardini (INSERM U1028, CNRS UMR5292) for their valuable help in neuroanatomy and neuroimaging analyses. Supported by grants BFU-06-12964 and BFU 09-14705 from (MINECO, Spain). 


\section{Figure captions}

Figure 1. Depiction of the structures of the medial temporal lobe (MTL) in a human brain rendering and coronal MRI image (inset) at the level denoted by the vertical line. The relevant segments of the MTL are shown with the same colour convention. Note the anteroposterior organization of the cortical fields, which make up the parahippocampal region (i.e. temporopolar, perirhinal and posterior parahippocampal cortices), and the presence of the amygdaloid complex buried at the dorsomedial portion of the MTL.

Figure 2. Lateral (A) and medial (B) surfaces of the human brain depicting connections between the medial temporal lobe (MTL) and cortical areas related to self-awareness networks (red arrows). Yellow arrows represent direct cortical outputs of the entorhinal cortex to cortical areas involved in self-awareness. The hippocampal formation and parahippocampal region are connected with areas that complete the network with the lateral prefrontal cortex, namely retrosplenial, superior temporal gyrus and parietal cortices (green arrows).

Abbreviations: ACC, anterior cingulate area; EC, entorhinal cortex; H, Hippocampus; INS insular cortex; ITG, inferior temporal gyrus; MFC, medial prefrontal cortex; OFC, orbitofrontal cortex; PC, parietal cortex; PFC, prefrontal cortex; PPHC, posterior parahippocampal cortex; PHR, Parahippocampal Region; RSC, retrosplenial cortex; STG, superior temporal gyrus; TPC, temporopolar cortex.

Figure 3. Diagram that shows relevant neuroanatomical connections of the medial temporal lobe (MTL) with the main regions of the cerebral cortex implicated in self-awareness. The MTL is here represented by 3 boxes: hippocampal formation, parahippocampal region and amygdala. Only the direct cortical connections are shown. The main cortical areas related to self-awareness 
converge to the entorhinal cortex. Then, the entorhinal cortex projects to the hippocampus via stepwise connections within the hippocampus itself. The hippocampal output is directed back to the entorhinal cortex, which relays the information to the parahippocampal region and other polysensory association cortices. On the right side of the figure, the amygdala sustains dense reciprocal connections with all the cortical areas related to the hippocampal formation. Red arrows indicate the main cortical relationship of and within the hippocampal formation; black arrows indicate the main amygdala connectivity with the hippocampal formation and cortical areas. The thickness of the arrows is indicative of the density of projections.

Abbreviations: CA1, Hippocampal fields CA1; CA3-CA2, Hippocampal fields CA3 and CA2; DG, Dentate Gyrus; PPHC, Posterior parahippocampal cortex; PRC, Perirhinal cortex; TPC, Temporopolar cortex; RSC, Retrosplenial cortex. 


\section{References}

Aggleton, J.P., 1993. The contribution of the amygdala to normal and abnormal emotional states. Trends Neurosci. 16, 28-33.

Amaral, D.G., Insausti, R., Cowan, W.M., 1983. Evidence for a direct projection from the superior temporal gyrus to the entorhinal cortex in the monkey. Brain Res. 275: 263-277.

Amaral, D.G., Price J.L., 1984. Amygdalo-cortical projections en the monkey (Macaca fascicularis). J. Comp. Neurol. 230, 465-496.

Amaral, D.G., Insausti, R., 1992. Retrograde transport of d- $\left[{ }^{3} \mathrm{H}\right]$-aspartate injected into the monkey amygdaloid complex. Exp. Brain. Res. 88, 375-388.

Amanzio, M., Monteverdi, S., Giordano, A., Soliveri, P., Filippi, P., Geminiani, G., 2010. Impaired awareness of movement disorders in Parkinson's disease. Brain and Cognition. 72, 337-346.

Amanzio, M., Torta, D.M., Sacco, K., Cauda, F., D'Agata, F., Duca, S., Leotta, D., Palermo, S., Geminiani, G.C., 2011. Unawareness of deficits in Alzheimer's disease: role of the cingulate cortex. Brain 134, 1061-1076.

Antoine, C., Antoine, P., Guermonprez, P., Frigard, B., 2004. Awareness of deficits and anosognosia in Alzheimer's disease. Encéphale 30, 570-577.

Blaizot, X., Landeau, B., Baron, J.C., Chavoix, C., 2000. Mapping the visual recognition memory network with PET in the behaving baboon. J. Cereb. Blood Flow Metab. 20, 213-219.

Blaizot, X., Meguro, K., Millien, I., Baron, J.C., Chavoix, C., 2002. Correlations between visual recognition memory and neocortical and hippocampal glucose metabolism after bilateral rhinal cortex lesions in the baboon: Implications for Alzheimer's disease. J. Neurosci. 22, 9166-9170.

Blaizot, X., Martinez-Marcos, A., Arroyo-Jiménez, M.M., Marcos, P., Artacho, E., Munoz, M., Chavoix, C., Insausti, R., 2004. The parahippocampal gyrus in the baboon: anatomical, cytoarchitectonic and MRI studies. Cerebral Cortex 14, 231-246.

Blaizot, X., Mansilla, F., Insausti, A.M., Constans, J.M., Salinas-Alamán, A., Pró-Sistiaga, P., Mohedano-Moriano, A., Insausti, R., 2010. The human parahippocampal region: I. Temporal pole cytoarchitectonic and MRI correlation. Cereb. Cortex 20, 2198-2212.

Braak, H., Braak, E., 1991. Neuropathological stageing of Alzheimer-related changes. Acta Neuropathol. 82, 239-259.

Braak, H., Braak, E., 1992. The human entorhinal cortex: normal morphology and laminaspecific pathology in various diseases. Neurosci. Res. 15, 6-31.

Braak, H., Braak, E., Yilmazer, D., de Vos, R.A., Jansen, E.N., Bohl, J., 1996. Pattern of brain destruction in Parkinson's and Alzheimer's diseases. J. Neural Transm. 103: 455-490.

Bramham, J., Morris, R.G., Hornak, J., Bullock, P., Polkey, C.E., 2009. Social and emotional functioning following bilateral and unilateral neurosurgical prefrontal cortex lesions. J. Neuropsychol. 3, 125-143.

Chavoix, C., Blaizot, X., Meguro, K., Landeau, B., Baron, J.C., 2002. Excitotoxic lesions of the rhinal cortex in the baboon differentially affect visual recognition memory, habit memory and spatial executive functions. Eur. J. Neurosci. 15, 1225 -1236.

Clare, L., Wilson, B.A., Carter, G., Roth, I., Hodges, J.R., 2002. Assessing awareness in earlystage Alzheimer's disease: Development and piloting of the Memory Awareness Rating Scale. Neuropsychol Rehabil 12, 341-362.

Clare, L., Marková, I.S., Roth, I., Morris, R.G., 2011. Awareness in Alzheimer's disease and associated dementias: theoretical framework and clinical implications. Aging Ment. Health 15, 936-944. 
Clare, L., Whitaker, C.J., Roberts, J.L., Nelis, S.M., Martyr, A., Marková, I.S., Roth, I., Woods, R.T., Morris, R.G., 2013. Memory awareness profiles differentiate mild cognitive impairment from early-stage dementia: evidence from assessments of performance monitoring and evaluative judgement. Dement. Geriatr. Cogn. Disord. 35, 266-279.

Corkin, S., Amaral, D.G., González, R.G., Johnson, K.A., Hyman, B.T., 1997. H. M.'s medial temporal lobe lesion: findings from magnetic resonance imaging. J. Neurosci. 17, 39643979.

Corkin, S., 2013. Permanent Present Tense: the unforgettable life of the amnesic patient, H. M., Penguin Books, New York.

Dalla Barba, G., Parlato, V., Iavarone, A., Boller, F., 1995. Anosognosia, intrusions and 'frontal' functions in Alzheimer's disease and depression. Neuropsychologia 33, 247-259.

Davachi, L., 2006. Item, context and relational episodic encoding in humans. Curr. Opin. Neurobiol. 16, 693-700.

Eickhoff, S.B., Stephan, K.E., Mohlberg, H., Grefkes, C., Fink, G.R., Amunts, K., Zilles, K., 2005. A new SPM toolbox for combining probabilistic cytoarchitectonic maps and functional imaging data. NeuroImage 25, 1325-1335.

Eslinger, P., Dennis, K., Moore, P., Antani, S., Hauck, R., Grossman, M., 2005. Metacognitive deficits in frontotemporal dementia. J/ Neurol/ Neurosurg/ Psychiatry 76, 1630-1635.

Flashman, L.A., 2002. Disorders of awareness in neuropsychiatric syndromes: an update. Curr. Psychiatry Rep. 4, 346-353.

Frankó, E., Insausti, A.M., Artacho-Pérula, E., Insausti, R., Chavoix, C., 2014. Identification of the human medial temporal lobe regions on magnetic resonance images. Hum. Brain Mapp. 35, 248-256.

Fuster, J.M., Alexander, G.E., 1971. Neuron activity related to short-term memory. Science (New York, NY) 173, 652-654.

Goldman-Rakic, P.S., 1992. Working memory and the mind. Scientific American 267, 110117.

Hainselin, M., Quinette, P., Desgranges, B., Martinaud, O., de La Sayette, V., Hannequin, D., Viader, F., Eustache, F., 2012. Awareness of disease state without explicit knowledge of memory failure in transient global amnesia. Cortex 48, 1079-1084.

Hodges, J.R., Patterson, K., 2007. Semantic dementia: a unique clinicopathological syndrome. Lancet Neurol. 6, 1004-1014.

Hoofien, D., Gilboa, A., Vakil, E., Barak, O., 2004. Unawareness of cognitive deficits and daily functioning among persons with traumatic brain injuries. J. Clin. Exp. Neuropsychol. 26,278-290.

Hornberger, M., Yew, B., Gilardoni, S., Mioshi, E., Gleichgerrcht, E., Manes, F., Hodges, J.R., 2014. Ventromedial-frontopolar prefrontal cortex atrophy correlates with insight loss in frontotemporal dementia and Alzheimer's disease. Hum. Brain Mapp. 35, 616-626.

Horrey, W.J., Lesch, M.F., Mitsopoulos-Rubens, E., Lee, J.D., 2015. Calibration of skill and judgment in driving: development of a conceptual framework and the implications for road safety. Accid. Anal. Prev. 76, 25-33.

Hyman, B.T., Van Hoesen, G.W., Damasio, A.R., Barnes, C.L., 1984. Alzheimers's disease: cell-speciphic pathology isolates the hippocampal formation. Science 225, 1168-1170.

Ichikawa, H., Ohno, H., Murakami, H., Ishigaki, S., Ohnaka, Y., Kawamura, M., 2013. Self-rated anosognosia score may be a sensitive and predictive indicator for progressive brain atrophy in amyotrophic lateral sclerosis: an X-ray computed tomographic study. Eur. Neurol. 69, 158-165.

Insausti, R., Amaral, D.G., Cowan, W.M., 1987a. The entorhinal cortex of the monkey: II. Cortical afferents. J. Comp. Neurol. 264, 356-395. 
Insausti, R., Amaral, D.G., Cowan, W.M., 1987b. The entorhinal cortex of the monkey: III. Subcortical afferents. J. Comp. Neurol. 264, 396-408.

Insausti, R., Tuñón, T., Sobreviela, T., Insausti, A.M., Gonzalo, L.M., 1995. The human entorhinal cortex. A cytoarchitectonic analysis. J. Comp. Neurol. 355, 171-198.

Insausti, R., Juottonen, K., Soininen, H., Insausti, A.M., Partanen, K., Vainio, P., Laakso, M.P., Pitkanen, A., 1998. MR volumetric analysis of the human entorhinal, perirhinal, and temporopolar cortices. AJNR Am. J. Neuroradiol. 19, 659-671.

Insausti, R., Munoz, M., 2001. Cortical projections of the non-entorhinal hippocampal formation in the cynomolgus monkey (Macaca fascicularis). Eur. J. Neurosci. 14, 435451.

Insausti, R., Amaral, D.G., 2008. Entorhinal cortex of the monkey: IV. Topographical and laminar organization of cortical afferents. J. Comp. Neurol. 509, 608-641.

Insausti, R., Amaral, D.G., 2012. The hippocampal formation. In: Mai, J.K., Paxinos, G. (Eds.), The human nervous system. 3rd ed. Amsterdam, Boston, Elsevier Academic Press, pp. 896-942.

Insausti, R., 2013. Comparative neuroanatomical parcellation of the human and nonhuman primate temporal lobe. J. Comp. Neurol. 521, 4163-4176.

Jacus, J.P., Dupont, M.P., Herades, Y., Pelix, C., Large, H., Baud, M., 2014. Awareness disorders in Alzheimer's disease and in mild cognitive impairment. Encephale. 40, 180187.

Jenkins, A.C., Mitchell, J.P., 2011. Medial prefrontal cortex subserves diverse forms of selfreflection. Soc. Neurosci. 6, 211-218.

Juottonen, K., Laakso, M.P., Insausti, R., Lehtovirta, M., Pitkanen, A., Partanen, K., Soininen, H., 1998. Volumes of the entorhinal and perirhinal cortices in Alzheimer's disease. Neurobiol. Aging 19, 15-22.

Kalbe, E., Salmon, E., Perani, D., Holthoff, V., Sorbi, S., Elsner, A., Weisenbach, S., Brand, M., Lenz, O., Kessler, J., Luedecke, S., Ortelli, P., Herholz, K., 2005. Anosognosia in very mild Alzheimer's disease but not in mild cognitive impairment. Dement. Geriatr. Cogn. Disord. 19, 349-356.

Kondo, H., Saleem, K.S., Price, J.L., 2003. Differential connections of the temporal pole with the orbital and medial prefrontal networks in macaque monkeys. J. Comp. Neurol. 465, 499-523.

Kudlicka, A., Clare, L., Hindle, J.V., 2013. Awareness of executive deficits in people with Parkinson's disease. J. Int. Neuropsychol. Soc. 19, 559-570.

Lancaster, J.L., Woldorff, M.G., Parsons, L.M., Liotti, M., Freitas, C.S., Rainey, L., Kochunov, P.V., Nickerson, D., Mikiten, S.A., Fox, P.T., 2000. Automated Talairach atlas labels for functional brain mapping. Hum. Brain Mapp. 10, 120-131.

Lavenex, P., Suzuki, W.A., Amaral, D.G., 2004. Perirhinal and parahippocampal cortices of the macaque monkey: Intrinsic projections and interconnections. J. Comp. Neurol. 472, 371-394.

Leritz, E., Loftis, C., Crucian, G., Friedman, W., Bowers, D., 2004. Self-awareness of deficits in Parkinson disease. Clin. Neuropsychol. 18, 352-361.

Maier, F., Williamson, K.L., Tahmasian, M., Rochhausen, L., Ellereit, A.L., Prigatano, G.P., Kracht, L., Tang, C.C., Herz, D.M., Fink, G.R., Timmermann, L., Eggers, C., 2016. Behavioural and neuroimaging correlates of impaired self-awareness of hypoand hyperkinesia in Parkinson's disease. Cortex.82, 35-47.

Marlowe, W.B., Mancal,1 E.L., Thomas, J.J., 1975. Complete Kluver-Bucy syndrome in man. Cortex 11, 53-59. 
Marshall, G.A., Kaufer, D.I., Lopez, O.L., Rao, G.R., Hamilton, R.L., DeKosky, S.T., 2004. Right prosubiculum amyloid plaque density correlates with anosognosia in Alzheimer's disease. J. Neurol. Neurosurg. Psychiatry 75, 1396-1400.

Meguro, K., Blaizot, X., Kondoh, Y., Le Mestric, C., Baron, J.C., Chavoix, C., 1999. Neocortical and hippocampal glucose hypometabolism following neurotoxic lesions of the entorhinal and perirhinal cortices in the non-human primate as shown by PET. Implications for Alzheimer's disease. Brain 122, 1519-1531.

Meunier, M., Bachevalier, J., Mishkin, M., Murray, E.A., 1993. Effects on visual recognition of combined and separate ablations of the entorhinal and perirhinal cortex in rhesus monkeys. J. Neurosci. 13, 5418-5432.

Meunier, M., Bachevalier, J., Murray, E.A., Málková, L., Mishkin, M., 1999. Effects of aspiration versus neurotoxic lesions of the amygdala on emotional responses in monkeys. Eur. J. Neurosci. 11, 403-418.

Meunier, M., Cirilli, L., Bachevalier, J., 2006. Responses to affective stimuli in monkeys with entorhinal or perirhinal cortex lesions. J. Neurosci. 26, 7718-7722.

Michon, A., Deweer, B., Pillon, B., Agid, Y., Dubois, B., 1994. Relation of anosognosia to frontal lobe dysfunction in Alzheimer's disease. J. Neurol. Neurosurg. Psychiatry 57, 805809.

Mohedano-Moriano, A., Munoz-López, M., Sanz-Arigita, E., Pró-Sistiaga, P., MartínezMarcos, A., Legidos-Garcia, M.E., Insausti, A.M., Cebada-Sánchez, S., Arroyo-Jiménez, M. del M., Marcos, P., Artacho-Pérula, E., Insausti, R., 2015. Prefrontal cortex afferents to the anterior temporal lobe in the Macaca fascicularis monkey. J. Comp. Neurol. 523, 2570-2598.

Morán, M.A., Mufson, E.J., Mesulam, M.M., 1987. Neural inputs into the temporopolar cortex of the rhesus monkey. J. Comp. Neurol. 256, 88-103.

Morone, G., Iosa, M., Pratesi, L., Paolucci, S., 2014. Can overestimation of walking ability increase the risk of falls in people in the subacute stage after stroke on their return home? Gait Posture 39, 965-970.

Morris, R.G, Mograbi, D.C., 2013. Anosognosia, autobiographical memory and selfknowledge in Alzheimer's disease. Cortex 49, 1553-1565.

Morris, R.G., Nelis, S.M., Martyr, A., Marková, I., Roth, I., Woods, R.T., Whitaker, C.J., Clare, L., 2016. Awareness of memory task impairment versus everyday memory difficulties in dementia. J. Neuropsychol. 10, 130-142.

Mufson, E.J., Binder, L., Counts, S.E., DeKosky, S.T., de Toledo-Morrell, L., Ginsberg, S.D., Ikonomovic, M.D., Perez, S.E., Scheff, S.W., 2012. Mild Cognitive Impairment: Pathology and mechanisms. Acta Neuropathol. 123, 13-30.

Muñoz, M., Insausti, R., 2005. Cortical efferents of the entorhinal cortex and the adjacent parahippocampal region in the monkey (Macaca fascicularis). Eur. J Neurosci 22, 13681388.

Northoff, G., Heinzel, A., de Greck, M., Bermpohl, F., Dobrowolny, H., Panksepp, J., 2006. Self-referential processing in our brain- A meta-analysis of imaging studies on the self. NeuroImage 31, 440-457.

Okonkwo, O.C., Wadley, V.G., Griffith, H.R., Belue, K., Lanza, S., Zamrini, E.Y., Harrell, L.E., Brockington, J.C., Clark, D., Raman, R., Marson, D.C., 2008. Awareness of deficits in financial abilities in patients with mild cognitive impairment: going beyond selfinformant discrepancy. Am. J. Geriatr. Psychiatry 16, 650-659.

Okonkwo, O.C., Griffith, H.R., Vance, D.E., Marson, D.C., Ball, K.K., Wadley, V.G., 2009. Awareness of functional difficulties in mild cognitive impairment: a multidomain assessment approach. J. Am. Geriatr. Soc. 57, 978-984. 
Olson, I.R., Plotzker, A., Ezzyat, Y., 2007. The Enigmatic temporal pole: a review of findings on social and emotional processing. Brain130, 1718-1731.

Perrotin, A., Desgranges, B., Landeau, B., Mézenge, F., La Joie, R., Egret, S., Pèlerin, A., de la Sayette, V., Eustache, F., Chételat, G., 2015. Anosognosia in Alzheimer disease: Disconnection between memory and self-related brain networks. Ann. Neurol. 78, 477486.

Pietracupa, S., Fasano, A., Fabbrini, G., Sarchioto, M., Bloise, M., Latorre, A., Altieri, M., Bologna, M., Berardelli, A., 2013. Poor self-awareness of levodopa-induced dyskinesias in Parkinson's disease: clinical features and mechanisms. Parkinsonism Relat. Disord. 19, 1004-1008.

Piguet, O., Hornberger, M., Shelley, B.P., Kipps, C.M., Hodges, J.R., 2009. Sensitivity of current criteria for the diagnosis of behavioral variant frontotemporal dementia. Neurology 78, 732-737.

Piras, F., Piras, F., Orfei, M.D., Caltagirone, C., Spalletta, G., 2016. Self-awareness in Mild Cognitive Impairment: Quantitative evidence from systematic review and meta-analysis. Neurosci. Biobehav. Rev. 61, 90-107.

Rauchs, G., Blaizot ,X., Giffard, C., Baron, J.C., Insausti, R., Chavoix, C., 2006. Imaging visual recognition memory network by PET in the baboon: Perirhinal cortex heterogeneity and plasticity after perirhinal lesion. J. Cereb. Blood Flow Metab. 26, 301-309.

Ries, M.L., McLaren, D.G., Bendlin, B.B., Guofanxu, Rowley, H.A., Birn, R., Kastman, E.K., Sager, M.A., Asthana, S., Johnson, S.C., 2012. Medial prefrontal functional connectivity-relation to memory self-appraisal accuracy in older adults with and without memory disorders. Neuropsychologia 50, 603-611.

Roberts, J.L., Clare, L., Wood,s R.T., 2009. Subjective memory complaints and awareness of memory functioning in mild cognitive impairment: a systematic review. Dement. Geriatr. Cogn. Disord. 28, 95-109.

Rosenbaum, R.S., Köhler, S., Schacter, D.L., Moscovitch M., Westmacott R., Black S.E., Gao F., Tulving E., 2005. The case of K.C.: contributions of a memory-impaired person to memory theory. Neuropsychologia 43, 989-1021.

Ruby, P., Decety, J., 2004. How would you feel versus how do you think she would feel? A neuroimaging study of perspective-taking with social emotions. J. Cogn. Neurosci. 16, 988-999.

Rymer, S., Salloway, S., Norton, L., Malloy, P., Correia, S., Monast, D., 2002. Impaired awareness, behavior disturbance, and caregiver burden in Alzheimer disease. Alzheimer Dis. Assoc. Disord. 16, 248-253.

Salmon, E., Perani, D., Herholz, K., Marique, P., Kalbe, E., Holthoff, V., Delbeuck, X., Beuthien-Baumann, B., Pelati, O., Lespagnard, S., Collette, F., Garraux, G., 2006. Neural correlates of anosognosia for cognitive impairment in Alzheimer's disease. Hum. Brain Mapp. 27, 588-597.

Schacter, D., 1991. Unawareness of deficit and unawareness of knowledge in patients with memory disorders, in: Prigatano, G.P., Schacter, D.L. (Eds.), Awareness of Deficit after Brain Injury: Clinical and Theoretical Issues. Oxford University Press, Oxford, pp. 127151

Shany-Ur, T., Lin, N., Rosen, H.J., Sollberger, M., Miller, B.L., Rankin, K.P., 2014. Selfawareness in neurodegenerative disease relies on neural structures mediating rewarddriven attention. Brain 137, 2368-2381.

Sitek, E.J., Thompson, J.C., Craufurd, D., Snowden, J.S., 2014. Unawareness of deficits in Huntington's disease. J. Huntingtons Dis. 3, 125-135. 
Sollberger, M., Rosen, H.J., Shany-Ur, T., Ullah, J., Stanley, C.M., Laluz, V., Weiner, M.W., Wilson, S.M., Miller, B.L., Rankin, K.P., 2014. Neural substrates of socioemotional selfawareness in neurodegenerative disease. Brain Behav. 4, 201-214.

Spargo, E., Everall, I.P., Lantos, P., 1993. Neuronal loss in the hippocampus in Huntington's disease: a comparison with HIV infection. J. Neuro.l Neurosurg. Psychiatry 56, 487-491.

Squire, L.R., Stark, C.E., Clark, R.E., 2004. The medial temporal lobe. Annu. Rev. Neurosci. 27, 279-306.

Starkstein, S.E., Jorge, R., Mizrahi, R., Robinson, R.G., 2006. A diagnostic formulation for anosognosia in Alzheimer's disease. J. Neuro.l Neurosurg. Psychiatry 77, 719-725.

Starkstein, S.E., 2014. Anosognosia in Alzheimer's disease: diagnosis, frequency, mechanism and clinical correlates. Cortex 61, 64-73.

Suzuki, W.A., Amaral, D.G., 1994. Perirhinal and parahippocampal cortices of the macaque monkey: cortical afferents J. Comp. Neurol. 350, 497-533.

van der Hulst, E.J., Bak, T.H., Abrahams, S., 2015. Impaired affective and cognitive theory of mind and behavioural change in amyotrophic lateral sclerosis. J. Neurol. Neurosurg. Psychiatry 86, 1208-1215.

Van Hoesen, G.W., Hyman, B.T., Damasio, A.R., 1991. Entorhinal cortex pathology in Alzheimer's disease. Hippocampus 1, 1-8.

Van Veluw, S.J., Chance, S.A., 2014. Differentiating between self and others: an ALE metaanalysis of fMRI studies of self-recognition and theory of mind. Brain Imaging Behav. 8, 24-38.

Vitale, C., Pellecchia, M.T., Grossi, D., Fragassi, N., Cuomo, T., Di Maio, L., Barone, P., 2001. Unawareness of dyskinesias in Parkinson's and Huntington's diseases. Neurol. Sci. 22, 105-106.

Vogel, A., Stokholm, J., Gade, A., Andersen, B.B., Hejl, A., Waldemar, G. 2004. Awareness of deficits in mild cognitive impairment and Alzheimer's disease: do MCI patients have impaired in-sight? Dement. Geriatr. Cogn. Disord. 17, 181-187.

Vogeley, K., Bussfeld, P., Newen, A., Herrmann, S., Happé, F., Falkai, P., Maier, W., Shah, N.J., Fink, G.R., Zilles, K., 2001. Mind reading: neural mechanisms of theory of mind and self-perspective. Neuroimage 14, 170-181.

Whitwell, J.L., Przybelski, S.A., Weigand, S.D., Ivnik, R.J., Vemuri, P., Gunter, J.L., Senjem, M.L., Shiung, M.M., Boeve, B.F., Knopman, D.S., Parisi, J.E., Dickson, D.W., Petersen, R.C., Jack, C.R., Josephs, K.A., 2009. Distinct anatomical subtypes of the behavioural variant of frontotemporal dementia: a cluster analysis study. Brain 132, 2932-2946.

Wild, K., Cotrell, V., 2003. Identifying driving impairment in Alzheimer disease: a comparison of self and observer reports versus driving evaluation. Alzheimer Dis. Assoc. Disord. 17, 27-34.

Wilson, B., Cockburn, J., Baddeley, A., Hiorns, R., 1989. The development and validation of a test battery for detecting and monitoring everyday memory problems. J. Clin. Exp. Neuropsychol. 11, 855-870.

Woolley, S.C., Moore, D.H., Katz, J.S., 2010. Insight in ALS: awareness of behavioral change in patients with and without FTD. Amyotroph. Lateral. Scler. 11, 52-56.

Zamboni, G., Drazich, E., McCulloch, E., Filippini, N., Mackay, C.E., Jenkinson M., Tracey I., Wilcock G.K., 2013. Neuroanatomy of impaired self-awareness in Alzheimer's disease and mild cognitive impairment. Cortex 49, 668-678. 
Figure 1

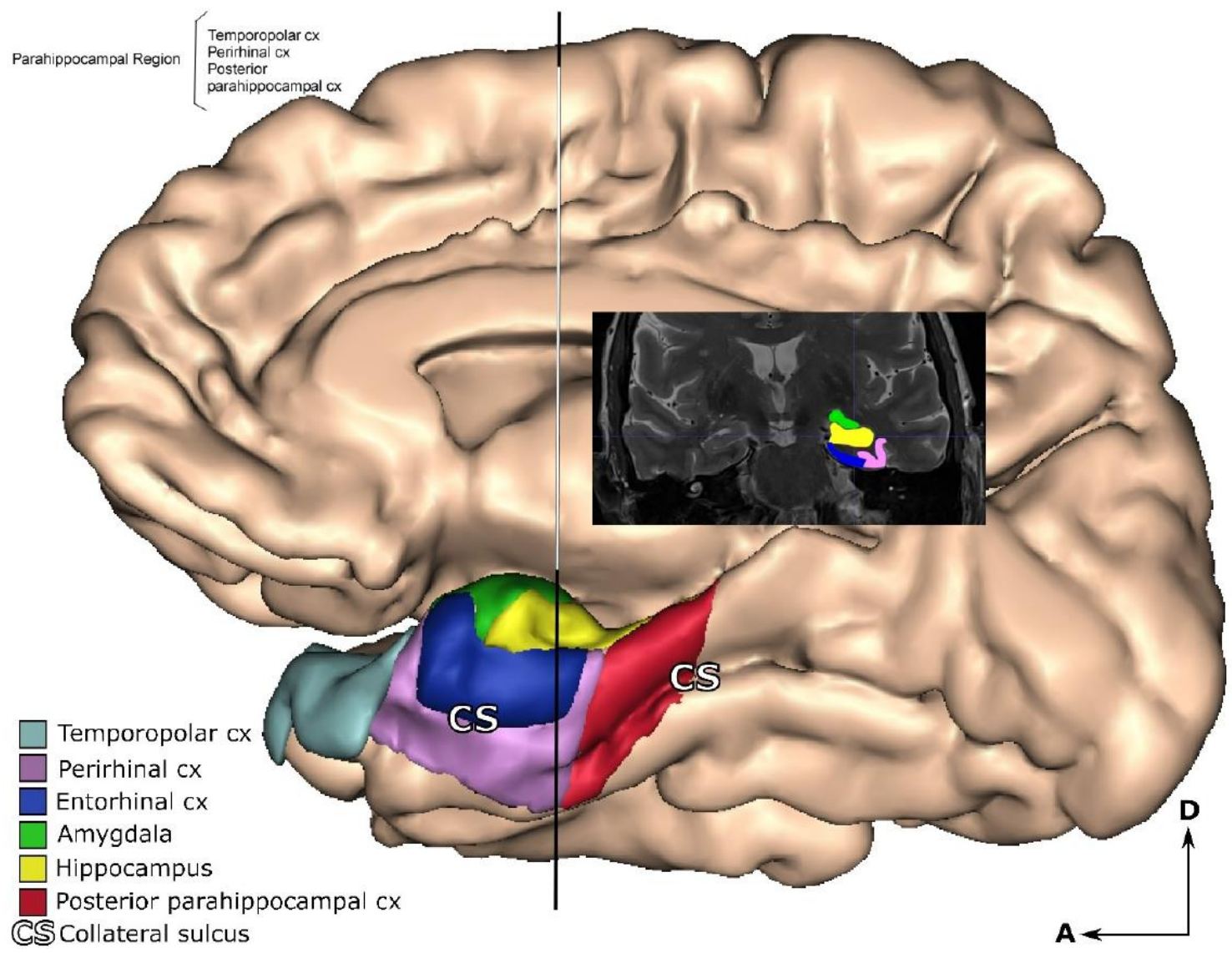


Figure 2

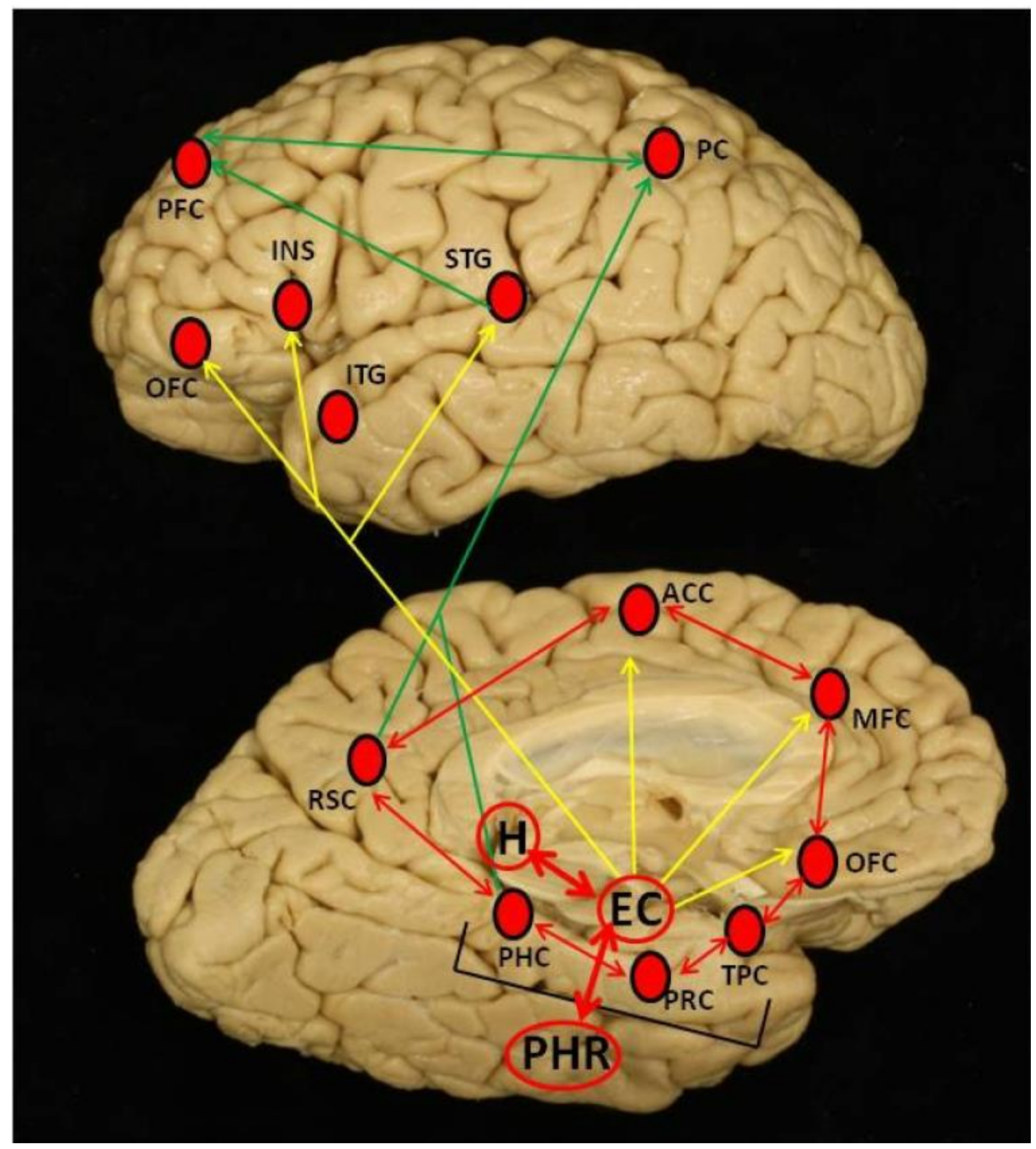


Figure 3

Hippocampal formation

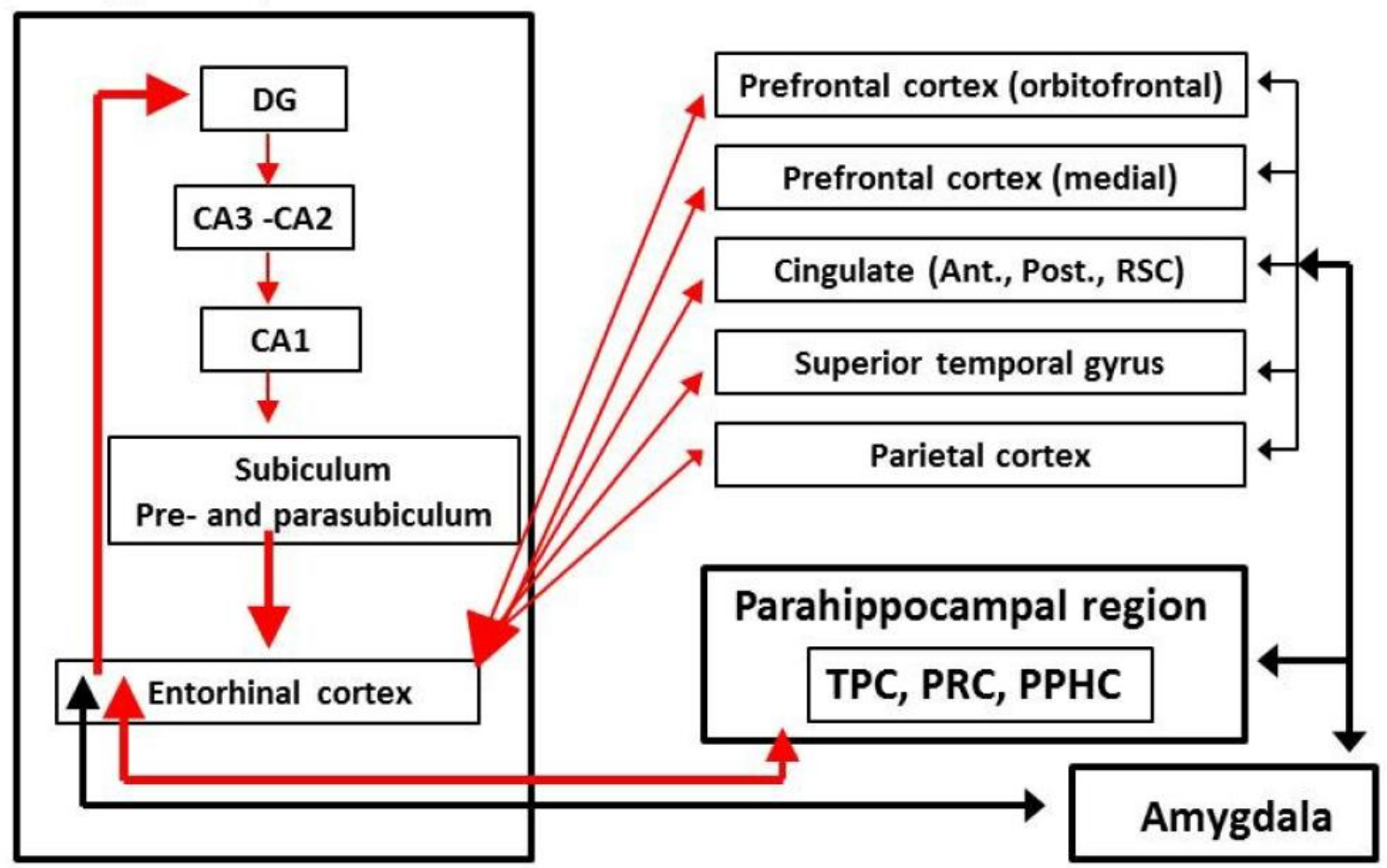


Table 1: Involvement of the medial temporal lobe (MTL) structures by domain of awareness

\begin{tabular}{|c|c|c|c|c|c|c|c|c|c|c|}
\hline & \multirow{2}{*}{$\begin{array}{l}\text { Object of } \\
\text { awarness }\end{array}$} & \multirow[t]{2}{*}{ Study population } & \multirow{2}{*}{$\begin{array}{c}\text { Neuroimage } \\
\text { technique }\end{array}$} & \multirow{2}{*}{$\begin{array}{l}\text { Methods for } \\
\text { assessing } \\
\text { awareness }\end{array}$} & \multirow{2}{*}{$\begin{array}{l}\text { Measures of } \\
\text { awareness }\end{array}$} & \multirow{2}{*}{$\begin{array}{l}\text { Findings } \\
\text { regarding } \\
\text { awareness }\end{array}$} & \multicolumn{2}{|c|}{ MTL structures involved } & \multirow{2}{*}{$\begin{array}{c}\text { Other brain } \\
\text { areas involved }\end{array}$} & \multirow[t]{2}{*}{ Reference } \\
\hline & & & & & & & $\begin{array}{c}\text { As shown in tables } \\
\text { or illustrative } \\
\text { images }\end{array}$ & $\begin{array}{c}\text { Neuroanatomically } \\
\text { contextualized } \\
\text { reinterpretation }\end{array}$ & & \\
\hline & Cognition & \begin{tabular}{|l}
$\mathrm{AD}$ patients \\
(intermediate or high \\
probability of $\mathrm{AD}$ ) \\
-13 aware of their \\
disturbances \\
-13 unaware of their \\
disturbances
\end{tabular} & $\begin{array}{l}\text { SP and NFT } \\
\text { counts } \\
\text { in } 4 \text { brain } \\
\text { regions: } \\
\text { superior and } \\
\text { middle frontal } \\
\text { gyri, STG, } \\
\text { ProS, and EC }\end{array}$ & $\begin{array}{l}\text { - Objective } \\
\text { measures of } \\
\text { cognitive } \\
\text { performance } \\
\text { - Clinical } \\
\text { interview by a } \\
\text { neurologist }\end{array}$ & $\begin{array}{l}\text { Rating on a 4- } \\
\text { point scale } \\
\text { based on } \\
\text { combination of } \\
\text { clinical } \\
\text { interview and } \\
\text { cognitive } \\
\text { performance }\end{array}$ & NIR & $\begin{array}{l}\text { SP density greater } \\
\text { in the } R \text { ProS of } \\
\text { unaware than } \\
\text { aware subjects }\end{array}$ & $\begin{array}{l}\text { R Rostralmost } \\
\text { portion of the HIPP } \\
\text { (subiculum) }\end{array}$ & $\begin{array}{l}\text { No other } \\
\text { significant } \\
\text { differences in } \\
\text { SP or NFT } \\
\text { density }\end{array}$ & $\begin{array}{l}\text { Marshall et } \\
\text { al., } 2004\end{array}$ \\
\hline & \multirow[t]{2}{*}{ Cognition } & \multirow[t]{2}{*}{$\begin{array}{l}209 \text { patients with mild } \\
\text { to moderate } \mathrm{AD}\end{array}$} & \multirow[t]{2}{*}{ FDG-PET } & \multirow[t]{2}{*}{$\begin{array}{l}13 \text { questions in } \\
\text { the cognitive } \\
\text { domain } \\
\text { completed by } \\
\text { patients and } \\
\text { caregivers }\end{array}$} & $\begin{array}{l}\text { Discrepancy } \\
\text { score between } \\
\text { caregiver's and } \\
\text { patient's } \\
\text { evaluations }\end{array}$ & $\begin{array}{l}\text { Caregivers } \\
\text { perceived greater } \\
\text { cognitive } \\
\text { impairment than } \\
\text { patients. }\end{array}$ & $\begin{array}{l}\text { No MTL structures } \\
\text { involved }\end{array}$ & & $\begin{array}{l}\text { Discrepancy } \\
\text { score negatively } \\
\text { correlated to } \\
\text { metabolism in } \\
\text { bilateral TPJ } \\
\text { and ITG, and L } \\
\text { SFG }\end{array}$ & \multirow[t]{2}{*}{$\begin{array}{l}\text { Salmon et } \\
\text { al., } 2006\end{array}$} \\
\hline 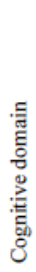 & & & & & $\begin{array}{l}\text { Patient's self- } \\
\text { evaluation }\end{array}$ & NIR & $\begin{array}{l}\text { Impaired self- } \\
\text { evaluation } \\
\text { positively } \\
\text { correlated to } \\
\text { metabolism in R } \\
\text { PHG }\end{array}$ & $R P R C$ & $\begin{array}{l}\text { Also correlated } \\
\text { to metabolism } \\
\text { in bilateral } \\
\text { OFC, L SFG, } \\
\text { and R gyrus } \\
\text { rectus, INS and } \\
\text { MTG }\end{array}$ & \\
\hline
\end{tabular}




\begin{tabular}{|c|c|c|c|c|c|c|c|c|c|}
\hline Cognition & $\begin{array}{l}29 \mathrm{AD} \text { patients: } \\
-15 \text { aware of their } \\
\text { disturbances } \\
-14 \text { unaware of their } \\
\text { disturbances }\end{array}$ & $\begin{array}{l}\text { fMRI during a } \\
\text { go/no-go task }\end{array}$ & $\begin{array}{l}30 \text { questions in } \\
\text { the cognitive } \\
\text { and behaviour } \\
\text { domains (AQ- } \\
\mathrm{D} \text { scale) } \\
\text { completed by } \\
\text { patients and } \\
\text { caregivers }\end{array}$ & $\begin{array}{l}\text { Discrepancy } \\
\text { score between } \\
\text { caregiver's and } \\
\text { patient's } \\
\text { evaluations }\end{array}$ & NIR & $\begin{array}{l}\text { Greater activation } \\
\text { in the R PHG in the } \\
\text { unaware } A D \\
\text { patients }\end{array}$ & RPPHC & $\begin{array}{l}\text { Lower } \\
\text { activation in the } \\
\text { R ACC, ant. } \\
\text { PFC, PoCG, } \\
\text { TPJ, L TL, } \\
\text { striatum and Cb } \\
\text { Greater } \\
\text { activation in the } \\
\text { R MTG, STG, } \\
\text { Cb, FFG, LING, } \\
\text { and bilateral } \\
\text { PCUN in the } \\
\text { unaware } \\
\text { patients }\end{array}$ & $\begin{array}{l}\text { Amanzio et } \\
\text { al., } 2011\end{array}$ \\
\hline Memory & $\begin{array}{l}12 \text { cognitively healthy } \\
\text { old adults } \\
12 \text { people with } \\
\text { memory impairment } \\
\text { ( } 7 \text { with } \mathrm{MCI} \text { and } 5 \\
\text { with early } \mathrm{AD} \text { ) }\end{array}$ & $\begin{array}{l}\text { fMRI during a } \\
\text { self-appraisal } \\
\text { task of } \\
\text { personality } \\
\text { trait }\end{array}$ & $\begin{array}{l}13 \text { items } \\
\text { regarding } \\
\text { everyday } \\
\text { situations } \\
\text { requiring } \\
\text { memory } \\
\text { (MARS } \\
\text { subscale) }\end{array}$ & $\begin{array}{l}\text { Discrepancy } \\
\text { scores on the } \\
\text { MARS task } \\
\text { between partner } \\
\text { and participant }\end{array}$ & $\begin{array}{l}\text { Participants with } \\
\text { memory } \\
\text { impairment } \\
\text { overestimated } \\
\text { their memory } \\
\text { abilities }\end{array}$ & $\begin{array}{l}\text { Greater } \\
\text { overestimation of } \\
\text { memory abilities } \\
\text { associated with } \\
\text { decreased MFC } \\
\text { functional } \\
\text { connectivity with } \\
\text { bilateral post. HIPP }\end{array}$ & $\begin{array}{l}\text { Posterior HIPP } \\
\text { bilaterally }\end{array}$ & $\begin{array}{l}\text { Also associated } \\
\text { with decreased } \\
\text { MFC } \\
\text { connectivity } \\
\text { with subgenual } \\
\text { ACC, other } \\
\text { MFC regions, } \\
\text { bilateral } \\
\text { DLPFC, and R } \\
\text { CAU }\end{array}$ & $\begin{array}{l}\text { Ries et al., } \\
2012\end{array}$ \\
\hline Cognition & $\begin{array}{l}17 \text { healthy older } \\
\text { adults } \\
17 \text { amnesic } \mathrm{MCI} \\
17 \mathrm{AD} \text { patients }\end{array}$ & $\begin{array}{l}\text { fMRI during a } \\
\text { self and other } \\
\text { appraisal } \\
\text { tasks }\end{array}$ & $\begin{array}{l}36 \text { Questions } \\
\text { on cognitive, } \\
\text { behavioural } \\
\text { and physical } \\
\text { traits) }\end{array}$ & $\begin{array}{l}\text { Discrepancy } \\
\text { scores between } \\
\text { partner and } \\
\text { participant }\end{array}$ & $\begin{array}{l}\text { Higher self } \\
\text { discrepancy } \\
\text { scores in } \mathrm{AD} \\
\text { patients than } \\
\text { controls and } \mathrm{MCI}\end{array}$ & $\begin{array}{l}\text { Lower activation } \\
\text { for self-awareness } \\
\text { in } \mathrm{AD} \text { patients than } \\
\text { in controls and } \\
\mathrm{MCI} \text {, in } \mathrm{L} \text { ant. } \mathrm{TL}\end{array}$ & L ant. HIPP & $\begin{array}{l}\text { Lower } \\
\text { activation in } \\
\text { MFC, and } \mathrm{L} \text { ant. } \\
\text { MTG and STG } \\
\text { in AD than in }\end{array}$ & $\begin{array}{l}\text { Zamboni et } \\
\text { al., } 2013\end{array}$ \\
\hline
\end{tabular}

\begin{tabular}{|c|c|c|c|c|c|c|c|c|c|}
\hline & & & $\begin{array}{l}\text { regarding } \\
\text { themselves and } \\
\text { their study } \\
\text { partner }\end{array}$ & & $\begin{array}{l}\text { for cognitive and } \\
\text { behavioural traits }\end{array}$ & for cognitive traits & & $\begin{array}{l}\text { controls and } \\
\mathrm{MCI} \text { in the self } \\
\text { condition only }\end{array}$ & \\
\hline Memory & $19 \mathrm{AD}$ patients & $\begin{array}{l}\text { - FDG-PET } \\
\text { - Resting-state } \\
\text { fMRI }\end{array}$ & $\begin{array}{l}\text { - Objective } \\
\text { measure of } \\
\text { episodic } \\
\text { memory } \\
\text { - Subjective } \\
\text { measure: } 9 \\
\text { items related } \\
\text { to memory } \\
\text { difficulties in } \\
\text { everyday life } \\
\text { (CDS scale) }\end{array}$ & $\begin{array}{l}\text { Discrepancy } \\
\text { score between } \\
\text { subjective and } \\
\text { objective } \\
\text { measures }\end{array}$ & $\begin{array}{l}\mathrm{AD} \text { patients } \\
\text { underestimated } \\
\text { their memory } \\
\text { deficits }\end{array}$ & $\begin{array}{l}\text { Positive } \\
\text { correlations } \\
\text { between delta- } \\
\text { score and OFC } \\
\text { connectivity with } \\
\text { the L HIPP and } \\
\text { PHG }\end{array}$ & $\begin{array}{l}L \text { ant. HIPP and } \\
\text { likely PRC }\end{array}$ & $\begin{array}{l}\text { Also correlated } \\
\text { with } \\
\text { - the OFC } \\
\text { connectivity } \\
\text { with the L } \\
\text { medial OFC } \\
\text { - the PCC } \\
\text { connectivity } \\
\text { with the L OFC }\end{array}$ & $\begin{array}{l}\text { Perrotin et } \\
\text { al., } 2015\end{array}$ \\
\hline
\end{tabular}




\begin{tabular}{|c|c|c|c|c|c|c|c|c|c|c|}
\hline 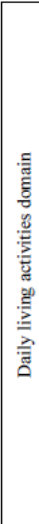 & \begin{tabular}{|l|} 
Functional \\
limitations
\end{tabular} & $\begin{array}{l}35 \text { patients with } \mathrm{AD} \\
44 \text { patients with FDT: } \\
-21 \text { with bvFTD } \\
-8 \text { with R-temporal } \\
\text { FTD } \\
-8 \text { with SD } \\
-7 \text { with PNFA } \\
46 \text { healthy controls }\end{array}$ & $\begin{array}{l}\text { structural } \\
\text { MRI }\end{array}$ & $\begin{array}{l}30 \text { items } \\
\text { encompassing } \\
\text { activities of } \\
\text { daily living, } \\
\text { cognitive } \\
\text { functioning, } \\
\text { social } \\
\text { interpersonal } \\
\text { functioning } \\
\text { and emotional } \\
\text { regulation } \\
\text { (PCRS scale) } \\
\text { completed by } \\
\text { participants } \\
\text { and informants }\end{array}$ & $\begin{array}{l}\text { Discrepancy } \\
\text { scores between } \\
\text { participant and } \\
\text { informant }\end{array}$ & $\begin{array}{l}\text { Overestimation } \\
\text { - in all domains in } \\
\text { bvFDT } \\
\text { - in the cognitive } \\
\text { domain in AD } \\
\text { - in the emotional } \\
\text { domain in AD } \\
\text { and PNFA } \\
\text { - in the } \\
\text { interpersonal } \\
\text { domain in PNFA } \\
\text { and R-temporal } \\
\text { FTD } \\
\text { No } \\
\text { overestimation in } \\
\text { SD }\end{array}$ & $\begin{array}{l}\text { Overestimation of } \\
\text { daily living } \\
\text { functioning related } \\
\text { to atrophy in the } \mathrm{R} \\
\text { HIPP, A and PHG }\end{array}$ & $\begin{array}{l}\text { R ant. } H, A \text { and } \\
P P H C\end{array}$ & $\begin{array}{l}\text { Also related to } \\
\text { atrophy in } \\
\text { widespread R } \\
\text { frontal regions, } \\
\text { INS, putamen, } \\
\text { thalamus, lateral } \\
\text { TL region, and } \\
\text { the pons }\end{array}$ & $\begin{array}{l}\text { Shany-Ur et } \\
\text { al., } 2014\end{array}$ \\
\hline 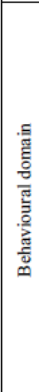 & Behaviour & $\begin{array}{l}29 \mathrm{AD} \text { patients } \\
-15 \text { aware of their } \\
\text { disturbances } \\
-14 \text { unaware of their } \\
\text { disturbances }\end{array}$ & $\begin{array}{l}\text { fMRI during a } \\
\text { go/no-go task }\end{array}$ & $\begin{array}{l}30 \text { questions in } \\
\text { the cognitive } \\
\text { and behaviour } \\
\text { domains (AQ- } \\
\text { D scale) } \\
\text { completed by } \\
\text { patients and } \\
\text { caregivers }\end{array}$ & $\begin{array}{l}\text { Discrepancy } \\
\text { score between } \\
\text { caregiver's and } \\
\text { patient's } \\
\text { evaluations }\end{array}$ & NIR & $\begin{array}{l}\text { Greater activation } \\
\text { in the } R P H G \text { in the } \\
\text { unaware } A D \\
\text { patients }\end{array}$ & $R P P H C$ & $\begin{array}{l}\text { Lower activity } \\
\text { in the R ACC, } \\
\text { ant. PFC, R } \\
\text { PoCG, TPJ, L } \\
\text { TL, striatum } \\
\text { and Cb } \\
\text { Greater } \\
\text { activation in the } \\
\text { R MTG, STG, } \\
\text { Cb, FFG, LING, } \\
\text { and bilateral } \\
\text { PCUN. }\end{array}$ & $\begin{array}{l}\text { Amanzio et } \\
\text { al., } 2011\end{array}$ \\
\hline
\end{tabular}




\begin{tabular}{|c|c|c|c|c|c|c|c|c|c|c|}
\hline \multirow{3}{*}{ 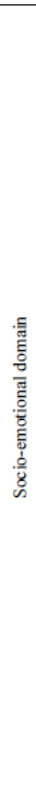 } & $\begin{array}{l}\text { Emotion } \\
\text { insight } \\
\text { (mainly } \\
\text { empathy) }\end{array}$ & \multirow[t]{2}{*}{$\begin{array}{l}13 \mathrm{AD} \text { patients } \\
37 \text { patients with FTD: } \\
-13 \text { with bvFTD } \\
-9 \text { with SD } \\
-8 \text { with PNFA } \\
-7 \text { with LPA }\end{array}$} & \multirow[t]{2}{*}{$\begin{array}{l}\text { structural } \\
\text { MRI }\end{array}$} & \multirow{2}{*}{$\begin{array}{l}28 \text { insight } \\
\text { items covering } \\
\text { social } \\
\text { interaction, } \\
\text { emotion, } \\
\text { diagnosis/treat } \\
\text { ment, language } \\
\text { and } \\
\text { motivation, } \\
\text { completed by } \\
\text { patients and } \\
\text { caregivers }\end{array}$} & \multirow[t]{2}{*}{$\begin{array}{l}\text { Discrepancy } \\
\text { score between } \\
\text { caregiver's and } \\
\text { patient's } \\
\text { judgment }\end{array}$} & $\begin{array}{l}\text { No group } \\
\text { differences with } \\
\text { post-hoc tests }\end{array}$ & $\begin{array}{l}\text { Atrophy in Left A } \\
\text { and HIPP }\end{array}$ & Left $A$ and ant. HIPP & $\begin{array}{l}\text { Atrophy in } \\
\text { bilateral } \\
\text { frontopolar } \\
\text { cortex and } \\
\text { ACC, R } \\
\text { DLPFC, and } \\
\text { SMA }\end{array}$ & \multirow[t]{2}{*}{$\begin{array}{l}\text { Homberger } \\
\text { et al., } 2014\end{array}$} \\
\hline & $\begin{array}{l}\text { Social } \\
\text { interaction }\end{array}$ & & & & & $\begin{array}{l}\text { Patients with } \\
\text { bvFTD showed } \\
\text { lower awareness } \\
\text { than patients with } \\
\text { PNFA and AD }\end{array}$ & $\begin{array}{l}\text { Atrophy in Right } \\
A \text { and L PHG }\end{array}$ & Right $A$ and $L P R C$ & $\begin{array}{l}\text { Atrophy in L } \\
\text { OFC, R MTG, } \\
\text { and bilateral } \\
\text { INS }\end{array}$ & \\
\hline & $\begin{array}{l}\text { Empathic } \\
\text { concern }\end{array}$ & $\begin{array}{l}23 \mathrm{AD} \text { patients } \\
12 \text { patients with } \mathrm{CBS} \\
48 \text { patients with } \mathrm{FTD} \text { : } \\
-28 \text { with bvFTD } \\
-16 \text { with } \mathrm{SD} \\
-4 \text { with } \mathrm{PNFA} \\
19 \text { older normal } \\
\text { controls }\end{array}$ & $\begin{array}{l}\text { structural } \\
\text { MRI }\end{array}$ & $\begin{array}{l}7 \text { items on } \\
\text { empathic } \\
\text { concern (IRI } \\
\text { subscale), } \\
\text { completed by } \\
\text { the patients } \\
\text { and informants }\end{array}$ & $\begin{array}{l}\text { Discrepancy } \\
\text { score between } \\
\text { informant's and } \\
\text { patient's } \\
\text { judgment }\end{array}$ & $\begin{array}{l}\text { Patients with } \\
\text { bvFTD and SD } \\
\text { overestimated } \\
\text { their level of } \\
\text { empathic concern } \\
\text { compared to } \\
\text { controls }\end{array}$ & $\begin{array}{l}\text { Overestimation of } \\
\text { one's empathic } \\
\text { concern: atrophy in } \\
\text { bilateral TP and R } \\
\text { ant. PHG } \\
\text { Underestimation of } \\
\text { one's empathic } \\
\text { concern ( } \mathrm{n}=72) \text { : } \\
\text { atrophy in L } \\
\text { anterior PHG (only } \\
\text { when uncorrected } \\
\text { for multiple } \\
\text { comparison)? }\end{array}$ & $\begin{array}{l}\text { Overestimation: } \\
\text { Bilateral TPC, } R \\
P R C, \text { maybe also } \\
\text { includes part of the } R \\
E C \\
\text { Underestimation: } L \\
\text { ant. HIPP }\end{array}$ & $\begin{array}{l}\text { Overestimation } \\
\text { of one's } \\
\text { empathic } \\
\text { concern: } R \text { ant. } \\
\text { ITG and L ant. } \\
\text { FF } \\
\text { Underestimatio } \\
n \text { of one's } \\
\text { empathic } \\
\text { concern: no } \\
\text { neuronal } \\
\text { correlates }\end{array}$ & $\begin{array}{l}\text { Sollberger et } \\
\text { al., } 2014\end{array}$ \\
\hline
\end{tabular}

Abbreviations: A: Amygdala; ACC: anterior cingulate cortex; AD: Alzheimer's disease; AQ-D: anosognosia questionnaire-dementia; bvFTD: behavioral variant frontotemporal dementia; CAU: caudate nucleus; $\mathrm{Cb}$ : cerebellum; CBS: corticobasal syndrome; CDS: Cognitive difficulties scale; DLPFC: dorsolateral prefrontal cortex; EC: entorhinal cortex; FFG: fusiform gyrus ; FTD, frontotemporal dementia; HIPP: hippocampus; INS: Insula; ITG: inferior temporal gyrus; IRI: interpersonal reactivity index; L: left; LING: lingual gyrus; LPA: logopenic progressive aphasia; MARS: memory awareness rating scale; MFC: medial prefrontal cortex; MTG: middle temporal gyrus; NFT: neurofibrillary tangles; NIR: nothing important to report; OFC: orbitofrontal cortex; PCC: posterior cingulate cortex; PCRS: Patient competency rating scale; PCUN: precuneus; PFC: prefrontal cortex; PPHC: posterior parahippocampal cortex; PHG: parahippocampal gyrus; PNFA: progressive non-fluent aphasia; PoCG: postcentral gyrus; PRC, perirhinal cortex; ProS : Prosubiculum; R: right; SD: semantic dementia; SFG: superior frontal gyrus; STG: superior temporal gyrus; SMA: supplementary motor area; SP: senile plaques; TL: temporal lobe; TP: temporal pole; TPC: temporopolar cortex; TPJ: temporo-parietal junction; SP : senile plaques. 


\section{Highlights}

- Most studies on self-awareness point to involvement of cortical midline structures

- Medial temporal lobe changes also occur in patients unaware of their disabilities

- The medial temporal lobe structures involved depend on the self-awareness domain

- The findings are discussed in view of the connectivity of the medial temporal lobe

- They are also discussed in the context of theoretical models of self-awareness 